\title{
Parametric Study for Performance of R.C. Wall with Opening using Analytical F.E. Model
}

\author{
By Alaa Morsy ${ }^{*} \&$ Youssef Ibrahim ${ }^{\dagger}$
}

Earthquake is a catastrophic event, which makes enormous harm to properties and human lives. R.C. walls are provided in structures to decrease horizontal displacements under seismic load. R.C walls in residential buildings might have openings that are required for windows, doors or different states of openings due to architectural purposes. Size, position, and area of openings may fluctuate from an engineering perspective and might have an impact on stiffness of R.C wall and on the structures seismic reaction. F.E. modeling approach has been conducted to study effects of opening shape, size and position in $R C$ wall with different thicknesses under axial \& lateral static loads. F.E. Method using "ANSYS" becomes an essential approach in analyzing civil engineering problems numerically. Now we can make various models with different parameters in short time by using ANSYS instead of examining it experimentally, which consumes much time and money. The proposed F.E approach has been verified with experimental programs conducted by other researchers and gives a perfect correlation between the model and experimental outputs including load capacity, failure mode, crack pattern and lateral displacement. A parametric study is applied to investigate effects of opening size, shape, orientation, aspect ratio, position with different R.C. wall thicknesses. After verifying the proposed F.E approach with other mathematical design models conducted by other researchers, a statistical analysis was performed on 38 F.E. specimens and is presented in this paper. Outcomes of this statistical analysis provide an overview of the performance of current design models and identify research gaps. The findings presented herein will be used to define a new mathematical formula to provide the ultimate axial load of R.C. wall with circular opening. This research may be useful for improving existing design models and to be applied in practice, as it satisfies both architectural and structural requirements.

Keywords: ANSYS, F.E.M., Opening, Seismic, Shear Wall.

\section{Introduction}

Shear walls are vertical structural elements designed to resist lateral forces exerted on a building by the lateral loads that may be induced by the effect of wind and earthquakes. But shear walls are frequently pierced for doors, windows and building services or other functional reasons. Openings are usually avoided in reinforced concrete structural elements because the size and location of openings in the shear wall may have adverse effect on seismic responses. These openings are also source of weak points and cause decrease inside the structure's stiffness and load-bearing capacity. As a designer, it is important to know the impacts of large openings sizes and configurations in

*Associate Professor, The Arab Academy for Science, Technology \& Maritime Transport, Egypt.
†Post Graduate Student, The Arab Academy for Science, Technology \& Maritime Transport, Egypt.

https://doi.org/10.30958/ajte.6-1-3

doi=10.30958/ajte.6-1-3 
shear wall on stiffness and also on seismic responses and behavior of structural system as a much amount of concrete and reinforcing steels has to be removed. So, an optimum configuration of openings in shear walls needs to be made (Lin and Kuo 1988).

Behavior of shear wall with openings has been studied in number of researches. Lin and Kuo (1988) conducted finite element analysis and experimental work to examine the ultimate strength of shear wall with openings under the effect of lateral load. The test program demonstrated the shear behavior of R.C. walls with different sizes of openings and reinforcing patterns around the opening. It was resolved that the shear capacity of the section is not only affected by the width of openings but also affected by the depth of openings as well which is not included in ACI Code.

Chowdhury et al. (2012) has modeled a six-storey frame-shear wall building using ETABS and studied the effects of openings in core type shear wall of thickness $203 \mathrm{~mm}$ under earthquake loads in equal static analysis. The results found out that stiffness and seismic response of the structure is affected by the dimensions of openings and position of openings in shear walls. It is also concluded that the more size of opening the more displacements conceded via building and this trend will increase with increasing storey level. Increasing wall thickness around the door openings are extra effective than that of window opening as far as displacement is concerned at top most story level. Furthermore, it is clearly definitely that opening in shear wall positioned in plane of loading is extra critical than that of opening in shear wall located out of plane of loading due to the fact that there is a significant change in displacement noticed after having opening in shear wall positioned in plane of loading.

Mosoarca (2014) analyzed the seismic behavior of shear walls with regular and staggered openings after the strong earthquake. He modeled a three-storey shear wall of thickness $120 \mathrm{~mm}$ on a scale of $1 / 3$ and statically loaded them with alternating cyclic horizontal loads. The study concluded that, with the same amount of reinforcement and layout, the walls with staggered openings developed a ductile failure, whereas the ones with regular openings developed a brittle failure; and the shear walls with staggered openings are more rigid and needed less reinforcement. Therefore, the opening location affects the shear wall capacity.

Musmar (2013) has modeled a five-storey frame-shear wall building using ANSYS and studied the effects of openings size in shear wall of thickness 300 $\mathrm{mm}$. The openings are placed in all stories at the mid length of shear walls. Adopted openings length is $1 \mathrm{~m}$, and the opening height is variable starting from $0.5 \mathrm{~m}$ to $3.0 \mathrm{~m}$ by $0.5 \mathrm{~m}$ increments. The study revealed that Small openings yield minor effects on the load capacity of shear walls, flexural stresses along the base level of shear walls, cracking pattern and maximum drifts. The larger the area of the opening is the extra is the stress flow disturbance within the shear wall. The study also conducted that when openings are large enough, the load capacity is reduced because stiffness of shear wall with openings decreases. 
Kankuntla et al. (2016) aimed to compare seismic performance of 15Storey with openings in shear wall situated in earthquake zone V. Seismic coefficient method and Response spectrum method were used for seismic analysis. SAP software was used and the results were compared. Location of shear wall was determined by changing shape configuration and areas of openings in shear wall for all buildings models. The study concluded that, the presence of openings in shear wall decreases the strength and rigidity of the shear wall depending on the sizes and shapes of opening. The column moment and axial force is increased as sizes of opening increase because of reduction of stiffness of shear wall with openings. The opening effect decreases as length of shear wall in plan increases. Moreover, the responses of structure are not affected by shapes of opening but the width and height of openings have significant effect. The frames with shear wall is stricken by the size of openings than their positions inside the shear walls on the stiffness and response of structure with opening size $\leq 15 \%$ of solid shear wall area. However, it is extensively impacted by the opening positions in shear walls with opening area $>15 \%$ of solid wall area.

Despite of the growing interest in modeling and analyzing behavior of shear walls, no researcher has yet seriously examined various parameters to have an optimum opening shape, orientation, aspect ratio, size, and position in RC wall, which could help designers in making openings either after construction or prior design. Consequently, by the use of ANSYS, the behavior of RC walls with openings can be explored. If the material properties have been implemented properly, ANSYS could simulate the elastic and plastic deformations that would take place in concrete till ultimately concrete crushing due to increasing the load.

\section{Research Scope and Objective}

The purpose of this study is to explore the behavior of shear walls with openings using finite element approach after being accurately verified experimentally and mathematically. The study includes a parametric study to gain an optimum opening shape, orientation, aspect ratio, size and position in R.C. wall with different thicknesses to increase capacity and dominance cracks. This paper is a part of a larger research study on the performance of opening configuration of shear wall openings and the use of fiber-reinforced polymers (FRPs) for strengthening those opening to enhance their behavior in opposing horizontal loads in high-rise buildings. The ongoing program is expected to significantly extend the findings of the previous studies and present a verified F.E. approach, which help for more research in this field. In addition, this paper conducts a new mathematical formula to predict the ultimate axial strength of the R.C. wall with circular opening. 
Table 1. Examined Parameters by F.E.M

\begin{tabular}{|c|c|c|c|c|c|c|c|}
\hline $\begin{array}{c}\text { Serial } \\
\text { No. }\end{array}$ & Shape & $\begin{array}{c}\text { Vertical } \\
\text { Dim. }\end{array}$ & $\begin{array}{l}\text { Horizontal } \\
\text { Dim. }\end{array}$ & Position & $\begin{array}{c}\text { Wall } \\
\text { Thickness (m) }\end{array}$ & $\begin{array}{c}\text { Aspect } \\
\text { Ratio }\end{array}$ & $\begin{array}{c}\text { Opening } \\
\text { size \% }\end{array}$ \\
\hline 1 & Square & 0.4 & 0.4 & Middle & 0.06 & 1.00 & $6.58 \%$ \\
\hline 2 & Square & 0.4 & 0.4 & Middle Right & 0.06 & 1.00 & $6.58 \%$ \\
\hline 3 & Square & 0.4 & 0.4 & Top Corner & 0.06 & 1.00 & $6.58 \%$ \\
\hline 4 & Square & 0.4 & 0.4 & Top Middle & 0.06 & 1.00 & $6.58 \%$ \\
\hline 5 & Square & 0.4 & 0.4 & Bottom Corner & 0.06 & 1.00 & $6.58 \%$ \\
\hline 6 & Square & 0.4 & 0.4 & Bottom Middle & 0.06 & 1.00 & $6.58 \%$ \\
\hline 7 & Square & 0.6 & 0.6 & Middle & 0.06 & 1.00 & $14.81 \%$ \\
\hline 8 & Square & 0.6 & 0.6 & Middle & 0.09 & 1.00 & $14.81 \%$ \\
\hline 9 & Square & 0.6 & 0.6 & Middle & 0.12 & 1.00 & $14.81 \%$ \\
\hline 10 & Square & 0.6 & 0.6 & Middle & 0.15 & 1.00 & $14.81 \%$ \\
\hline 11 & Square & 0.6 & 0.6 & Middle & 0.18 & 1.00 & $14.81 \%$ \\
\hline 12 & Square & 0.6 & 0.6 & Middle & 0.21 & 1.00 & $14.81 \%$ \\
\hline 13 & Square & 0.6 & 0.6 & Middle & 0.24 & 1.00 & $14.81 \%$ \\
\hline 14 & Square & 0.6 & 0.6 & Middle & 0.27 & 1.00 & $14.81 \%$ \\
\hline 15 & Square & 0.8 & 0.8 & Middle & 0.06 & 1.00 & $26.34 \%$ \\
\hline 16 & Square & 1.0 & 1.0 & Middle & 0.06 & 1.00 & $41.15 \%$ \\
\hline 17 & Square & 1.2 & 1.2 & Middle & 0.06 & 1.00 & $59.26 \%$ \\
\hline 18 & Rectangle & 0.8 & 0.2 & Middle & 0.06 & 0.25 & $6.58 \%$ \\
\hline 19 & Rectangle & 0.2 & 0.8 & Middle & 0.06 & 4.00 & $6.58 \%$ \\
\hline 20 & Rectangle & 0.8 & 0.4 & Middle & 0.06 & 0.50 & $13.17 \%$ \\
\hline 21 & Rectangle & 0.4 & 0.8 & Middle & 0.06 & 2.00 & $13.17 \%$ \\
\hline 22 & Rectangle & 1 & 0.6 & Middle & 0.06 & 0.60 & $24.69 \%$ \\
\hline 23 & Rectangle & 0.6 & 1 & Middle & 0.06 & 1.67 & $24.69 \%$ \\
\hline 24 & Rectangle & 1 & 1.4 & Middle & 0.06 & 1.40 & $57.61 \%$ \\
\hline 25 & Rectangle & 0.4 & 1 & Middle & 0.06 & 2.50 & $16.46 \%$ \\
\hline 26 & Rectangle & 1 & 0.4 & Middle & 0.06 & 0.40 & $16.46 \%$ \\
\hline 27 & Rectangle & 0.8 & 0.6 & Middle & 0.06 & 0.75 & $19.75 \%$ \\
\hline 28 & Rectangle & 0.8 & 0.6 & Middle & 0.09 & 0.75 & $19.75 \%$ \\
\hline 29 & Rectangle & 0.8 & 0.6 & Middle & 0.12 & 0.75 & $19.75 \%$ \\
\hline 30 & Rectangle & 0.8 & 0.6 & Middle & 0.15 & 0.75 & $19.75 \%$ \\
\hline 31 & Rectangle & 0.8 & 0.6 & Middle & 0.18 & 0.75 & $19.75 \%$ \\
\hline 32 & Rectangle & 0.8 & 0.6 & Middle & 0.21 & 0.75 & $19.75 \%$ \\
\hline 33 & Rectangle & 0.8 & 0.6 & Middle & 0.24 & 0.75 & $19.75 \%$ \\
\hline 34 & Rectangle & 0.8 & 0.6 & Middle & 0.27 & 0.75 & $19.75 \%$ \\
\hline 35 & Rectangle & 0.6 & 0.8 & Middle & 0.06 & 1.33 & $19.75 \%$ \\
\hline 36 & Rectangle & 0.4 & 1.2 & Middle & 0.06 & 3.00 & $19.75 \%$ \\
\hline 37 & Rectangle & 0.5 & 0.8 & Middle & 0.06 & 1.60 & $16.46 \%$ \\
\hline 38 & Rectangle & 0.3 & 1.2 & Middle & 0.06 & 4.00 & $14.81 \%$ \\
\hline 39 & Rectangle & 0.5 & 1 & Middle & 0.06 & 2.00 & $20.58 \%$ \\
\hline 40 & Rectangle & 0.7 & 0.8 & Middle & 0.06 & 1.14 & $23.05 \%$ \\
\hline 41 & Rectangle & 0.5 & 1.2 & Middle & 0.06 & 2.40 & $24.69 \%$ \\
\hline 42 & Rectangle & 0.5 & 0.6 & Middle & 0.06 & 1.20 & $12.35 \%$ \\
\hline 43 & Rectangle & 0.3 & 0.6 & Middle & 0.06 & 2.00 & $7.41 \%$ \\
\hline 44 & Rectangle & 0.3 & 1.4 & Middle & 0.06 & 4.67 & $17.28 \%$ \\
\hline 45 & Rectangle & 0.3 & 1.4 & Middle & 0.06 & 4.67 & $17.28 \%$ \\
\hline 46 & Rectangle & 0.3 & 0.8 & Middle & 0.06 & 2.67 & $9.88 \%$ \\
\hline 47 & Rectangle & 0.4 & 0.6 & Middle & 0.06 & 1.50 & $9.88 \%$ \\
\hline 48 & Rectangle & 0.2 & 1.2 & Middle & 0.06 & 6.00 & $9.88 \%$ \\
\hline 49 & Rectangle & 0.3 & 1 & Middle & 0.06 & 3.33 & $12.35 \%$ \\
\hline
\end{tabular}




\begin{tabular}{|c|c|c|c|c|c|c|c|}
\hline 50 & Rectangle & 0.2 & 1.4 & Middle & 0.06 & 7.00 & $11.52 \%$ \\
\hline 51 & Rectangle & 0.7 & 0.4 & Middle & 0.06 & 0.57 & $11.52 \%$ \\
\hline 52 & Rectangle & 0.5 & 0.4 & Middle & 0.06 & 0.80 & $8.23 \%$ \\
\hline 53 & Rectangle & 0.6 & 0.4 & Middle & 0.06 & 0.67 & $9.88 \%$ \\
\hline 54 & Rectangle & 1.2 & 0.2 & Middle & 0.06 & 0.17 & $9.88 \%$ \\
\hline 55 & Rectangle & 0.2 & 0.4 & Middle & 0.06 & 2.00 & $3.29 \%$ \\
\hline 56 & Rectangle & 0.6 & 1.2 & Middle & 0.06 & 2.00 & $29.63 \%$ \\
\hline 57 & Circular & Diameter & 0.8 & Middle & 0.06 & - & $20.67 \%$ \\
\hline 58 & Circular & Diameter & 0.6 & Middle & 0.06 & - & $11.63 \%$ \\
\hline 59 & Circular & Diameter & 0.7 & Middle & 0.06 & - & $15.83 \%$ \\
\hline 60 & Circular & Diameter & 0.5 & Middle & 0.06 & - & $8.08 \%$ \\
\hline 61 & Circular & Diameter & 0.9 & Middle & 0.06 & - & $26.17 \%$ \\
\hline 62 & Circular & Diameter & 0.45 & Middle & 0.06 & - & $6.54 \%$ \\
\hline
\end{tabular}

\section{Methodology}

The research plan includes three phases, the first phase; includes verification of the experimental results conducted by other researchers using an ANSYS model and ensure the correlation between both F.E. and experimental results for load capacity, failure mode and lateral displacement. The research depends on two different experimental programs using three different F.E models to be more confident with the model results.

The second phase; After the model has been verified with the experimental outputs, a parametric study has been conducted by changing opening shape, opening location, size of opening, aspect ratio of opening, rectangular opening orientation and changing R.C. wall thickness. Table 1 shows the details of the examined parameters and its variation. So that a number of 62 different F.E. model have been conducted on ANSYS for such study.

The third phase includes verification between the F.E approach and other mathematical design models. Then, a statistical analysis is performed on 38 F.E. specimens to validate the accuracy of the current mathematical design models. Based on the results of this statistical analysis, an overview is provided on the performance of current design models and to identify research gaps. The results will be used to conduct a new mathematical formula to get the ultimate axial load of R.C wall with circular opening.

\section{Finite Element Analysis of Shear Wall with Openings}

ANSYS finite element software is used to model two experimental programs of reinforced concrete shear loaded in the model up to failure, which have a symmetric opening (Popescu et al. 2016) and (Mohammed et al. 2010). Nonlinear response of RC wall is developed by cracking, plastic deformations in compression, crushing of the concrete and plastic deformations of the reinforcement. 


\section{Experimental Data Used for Model Verification}

\section{$\underline{\text { First Model Verification }}$}

Two shear wall specimens named I-L and I-S designed to represent typical wall panels in residential buildings $(1800 \mathrm{~mm}$ long, $1350 \mathrm{~mm}$ tall and $60 \mathrm{~mm}$ thick), modeled for testing to failure, they have symmetric openings ( $900 \mathrm{~mm} \mathrm{x}$ $1050 \mathrm{~mm}) \&(450 \mathrm{~mm} \times 1050 \mathrm{~mm})$ as shown in Figures 1 and 2. The specimens are designed to be load-bearing concrete walls that are loaded by vertical loads with no transverse loads between supports or lateral in-plane forces. Welded wire fabric reinforcement was used to reinforce the walls, comprising of deformed $5 \mathrm{~mm}$ diameter bars with $100 \mathrm{~mm}$ spacing in both orthogonal directions and centrally positioned in a single layer. The concrete utilized to cast the specimens was a self-consolidating blend that could be poured without vibrating it. The average cubic compressive strength of the concrete was 62.8 $\mathrm{MPa}$. Steel mean yield strength (fy) was $632 \mathrm{MPa}$.

Four hydraulic jacks, each with a most extreme limit of $1400 \mathrm{kN}$, were connected together to apply a uniformly distributed load, with controlled total force, along the wall length. An eccentricity of one sixth of the wall thickness was applied in the loading. A steel rod was welded to both of loading beam in order to apply eccentric distributed loading, designed to fit into a guide system connected to the upper edge and lower edge of the specimen as illustrated in Figure 1 and 2 (Popescu et al. 2016).

Figure 1. I-L Specimen Test Setup

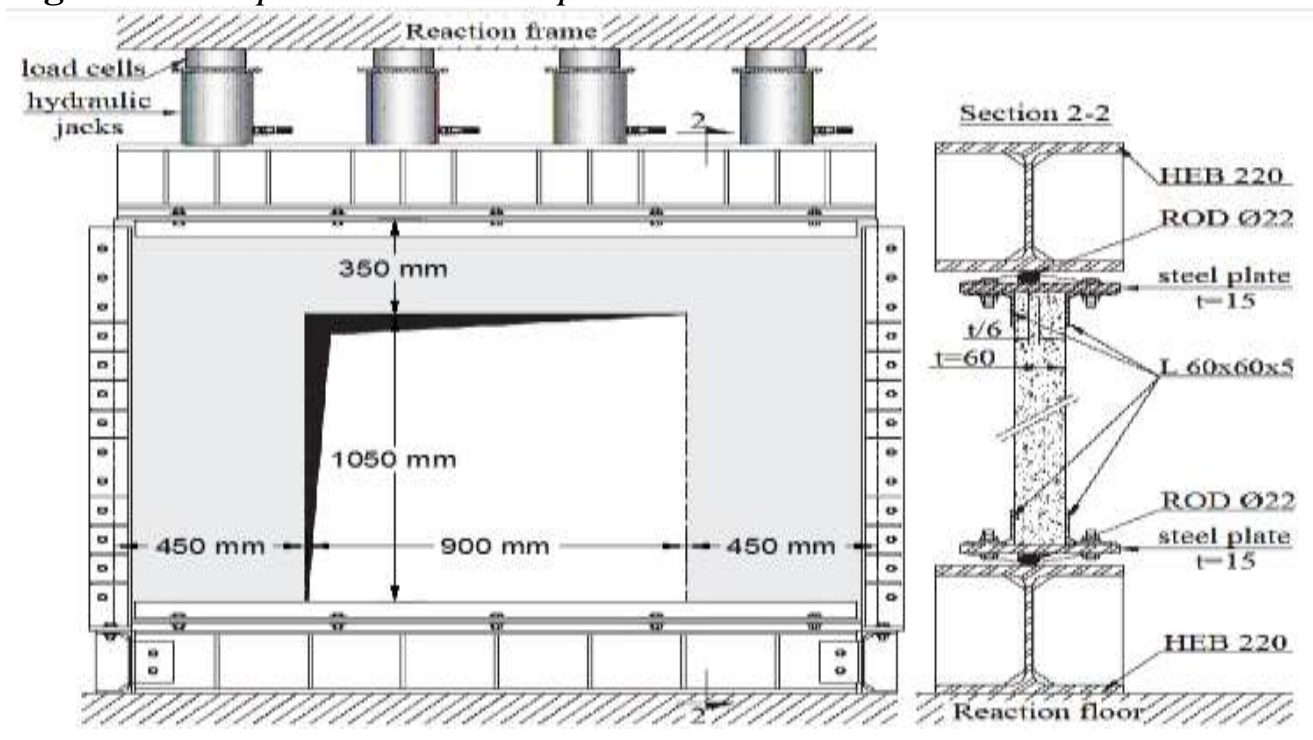


Figure 2. I-S Specimen Test Setup

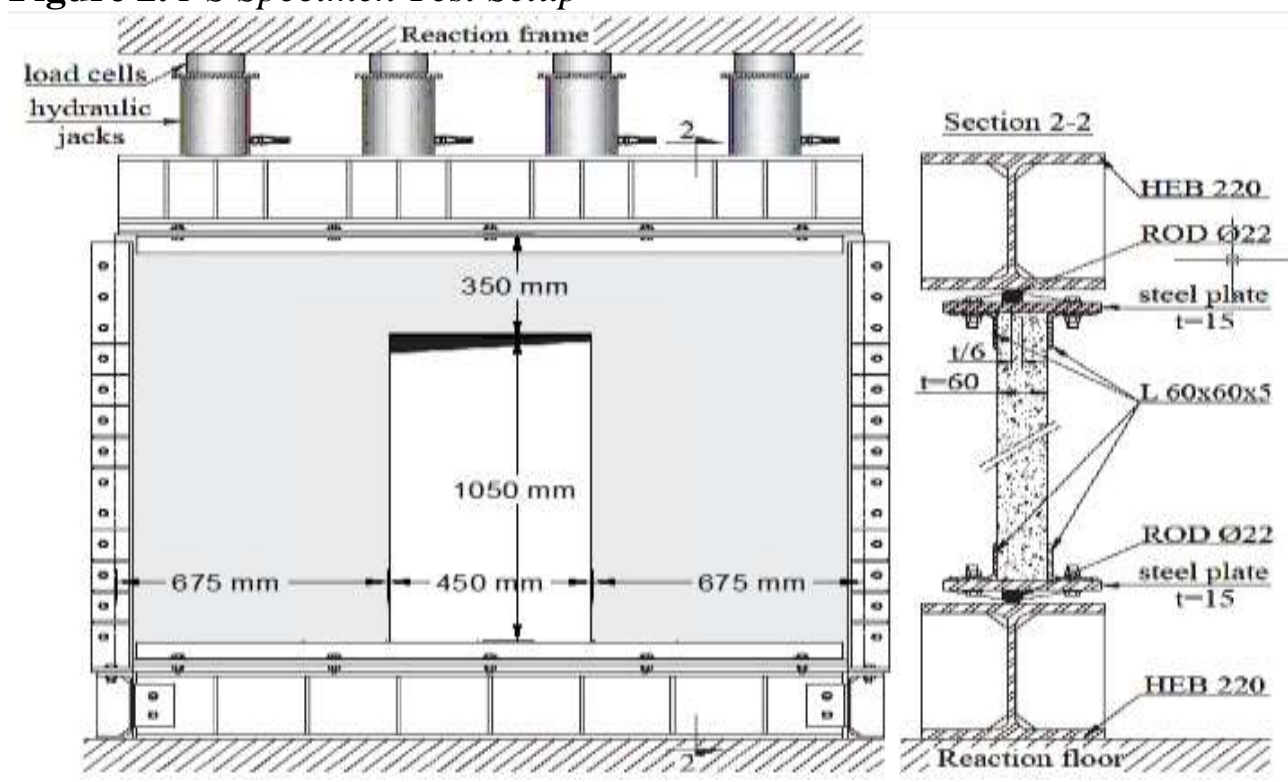

$\underline{\text { Second Model Verification }}$

A shear wall specimen named $\mathrm{WO} 2$ designed to represent typical wall (400mm long, $800 \mathrm{~mm}$ tall and $50 \mathrm{~mm}$ thick), modeled for testing to failure, it has a symmetric opening $(135 \mathrm{~mm} \times 240 \mathrm{~mm})$ as shown in Figure 3 . The specimen was cast with constant thickness. The specimen is designed to be a load-bearing concrete wall that is loaded by vertical loads with no transverse loads between supports or lateral in-plane forces. Welded wire fabric reinforcement was used to reinforce the walls, consisting of deformed $5 \mathrm{~mm}$ diameter bars and centrally positioned in a single layer. The concrete used to cast the specimens was a selfconsolidating blend that could be poured without vibrating it. The average cubic compressive strength of the concrete was $22.11 \mathrm{MPa}$. Steel mean yield strength (fy) was 478MPa.

A hydraulic jack with a most extreme limit of $300 \mathrm{kN}$, applies a uniformly distributed load, with controlled total force, along the wall length. An eccentricity of one sixth of the wall thickness was applied in the loading. A steel rod was welded to both of loading beam in order to apply eccentric distributed loading, designed to fit into a guide system connected to the upper edge and lower edge of the specimen as illustrated in Figure 3 (Mohammed et al. 2010). 
Figure 3. Test Setup of WO2 Specimen (Mohammed et al. 2010)

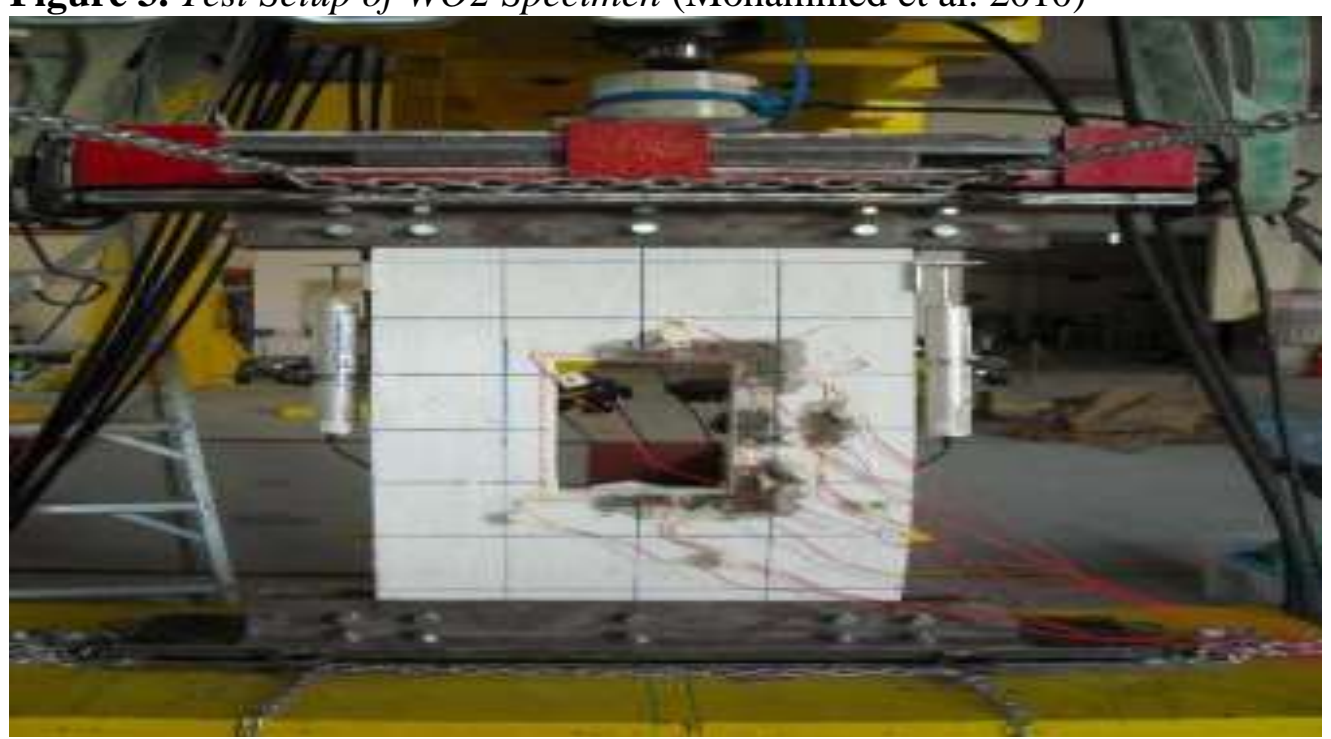

\section{Material Model}

\section{Modeling of Concrete}

The nonlinear response of reinforced concrete is modeled by solid65 element. The concrete material is modeled by this element, which primarily based on a constitutive model for the triaxial behavior of concrete after Williams and Warnke (1975). This element is isoperimetric element which is characterized by eight nodes, each having three translation degrees of freedom in the nodal $\mathrm{x}, \mathrm{y}$ and $\mathrm{z}$-directions. The geometry, node positions and the coordinate system for the element is appeared in Figure 4. It is able to simulate plastic and elastic deformation, crushing in compression and cracking in tension in three perpendicular directions at each integration point as the load is increased (Morsy et al. 2015).

Figure 4. Solid 65 Element

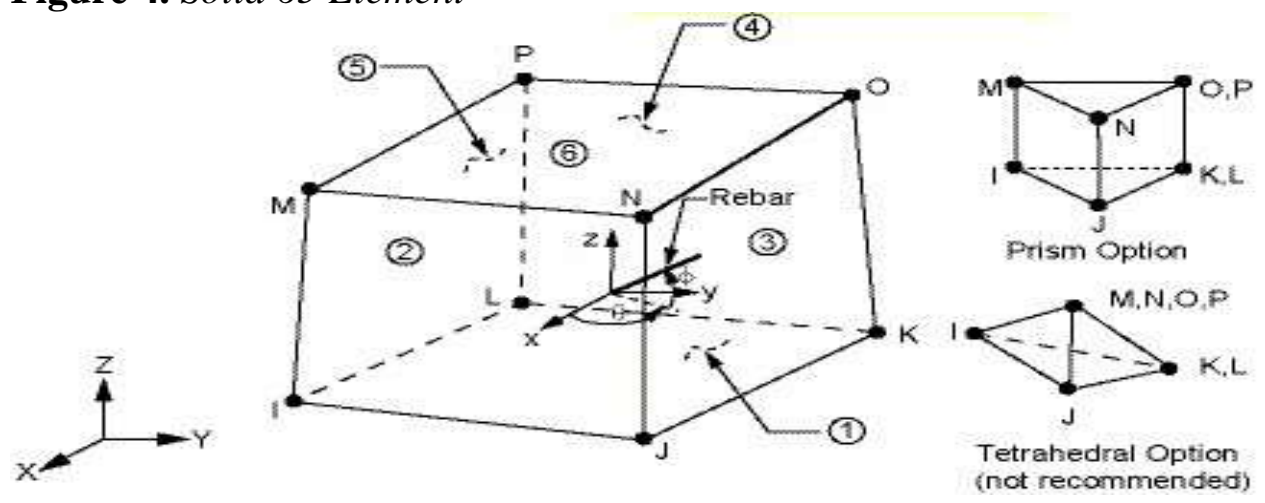

Changing the element stiffness matrices conducts an adjustment in the material properties, which helps in the cracking modeling. In Solid 65, 
crushing is known as the complete deterioration of the structural integrity of the material (material spalling). If the material fails at an integration point in uniaxial, biaxial or triaxial compression, the material is assumed to be crushed at that point. The von Mises failure criterion is used to model the multi-linear isotropic concrete along with Willam and Warnke model to define the failure of concrete.

The multi-linear isotropic stress-strain curve for the concrete is computed by the use of the following equations (Chinese Standard, 2002) ${ }^{1} \&$ Rusch model (Rusch and Hilsdorf 1963) in order to obtain the compressive uniaxial stress-strain relationship for the concrete model.

When fcu $>50 \mathrm{MPa}$

When fcu $<50 \mathrm{MPa}$

$$
\begin{array}{cc}
\begin{array}{l}
\sigma_{\mathrm{c}}=f_{\mathrm{c}}\left[1-\left(1-\frac{\varepsilon_{\mathrm{c}}}{i_{\mathrm{c}}}\right)^{n}\right] \begin{array}{c}
\varepsilon_{\mathrm{c}} \leqslant \varepsilon_{0} \\
\varepsilon_{\mathrm{c}}<\varepsilon_{\mathrm{c}} \leqslant \varepsilon_{\mathrm{cu}}
\end{array} \\
\sigma_{\mathrm{c}}=f_{\mathrm{c}}
\end{array} & \sigma_{\mathrm{c}}=f_{\mathrm{c}}\left[2 \frac{\varepsilon_{\mathrm{c}}}{\varepsilon_{0}}-\left(\frac{\varepsilon_{\mathrm{c}}}{\varepsilon_{0}}\right)^{2}\right] \quad\left(\varepsilon_{\mathrm{c}} \leqslant \varepsilon_{0}\right) \\
n=2-\frac{1}{60}\left(f_{\mathrm{cu}}-50\right) & \sigma_{\mathrm{c}}=f_{\mathrm{c}} \quad\left(\varepsilon_{0}<\varepsilon_{\mathrm{c}} \leqslant \varepsilon_{\mathrm{cu}}\right) \\
\varepsilon_{0}=0.002+0.5\left(f_{\mathrm{cu}}-50\right) \times 10^{-5} & \\
\varepsilon_{\mathrm{cu}}=0.0033-\left(f_{\mathrm{cu}}-50\right) \times 10^{-5} &
\end{array}
$$

Where:

$\sigma_{\mathrm{c}}$ : the stress in concrete corresponding to the compressive strain $\varepsilon_{\mathrm{c}}$

$\mathrm{f}_{\mathrm{c}}$ : the axial compressive strength of concrete

$\varepsilon_{0}$ : the compressive strain corresponding to $\mathrm{f}_{\mathrm{c}}$

\begin{tabular}{|c|c|c|}
\hline & $\begin{array}{c}1^{\text {st }} \\
\text { experimental } \\
\text { program }\end{array}$ & $\begin{array}{c}2^{\text {nd }} \\
\text { experimental } \\
\text { program }\end{array}$ \\
\hline Modulus of elasticity "MPa" & 41236.18 & 16761.59 \\
\hline Poisson's ratio & 0.2 & 0.2 \\
\hline $\begin{array}{l}\text { Shear transfer coefficients for an open crack } \\
(\beta \mathrm{t})\end{array}$ & 0.5 & 0.5 \\
\hline $\begin{array}{l}\text { Shear transfer coefficients for a closed crack } \\
(\beta \mathrm{c})\end{array}$ & 1 & 1 \\
\hline Uniaxial tensile cracking stress (fr) "MPa" & 6.28 & 2.21 \\
\hline Uniaxial crushing stress (fc) "MPa" & 62.8 & 22.11 \\
\hline
\end{tabular}

$\varepsilon_{\mathrm{cu}}$ : the ultimate compressive strain

$\mathrm{f}_{\mathrm{cu}}$ : the cube strength of concrete

$\mathrm{n}$ : a parameter

Table 2. Concrete Properties prior to Initial Yield Surface

States of the crack face is represented by the shear transfer coefficient $\beta$. $\beta$ starts from 0 to 1 , with 0 indicating a smooth crack (complete loss of shear transfer) and 1 indicating a rough crack (no loss of shear transfer) (Kwan et al.

\footnotetext{
${ }^{1}$ Chinese Standard 'GB 50010-2002' (2002) Code for Design of Concrete Structures.
} 
1999, Terec et al. 2010). Table 2 lists concrete properties within Solid65 element.

\section{Modeling of Steel Reinforcement}

The link8 element models the nonlinear response of reinforcement bars which may be included in the finite element model as a discrete model (individual bars). As shown in Figure 5, prior to initial yield surface steel material model is linear elastic, after the initial yield surface it is completely plastic, in compression and tension loading. Figure 6 shows the geometry, node positions and the coordinate system for the element. The parameters selected to define the material properties of steel are given in Table 3.

Table 3. Material Properties for Steel

\begin{tabular}{|c|c|c|}
\hline \multicolumn{3}{|c|}{ Linear Isotropic } \\
\hline Es "MPa" & \multicolumn{2}{c|}{0.3} \\
\hline Poisson's ratio & \multicolumn{2}{|c|}{0.300} \\
\hline & Bilinear Isotropic \\
\hline & $\begin{array}{c}\mathbf{1}^{\text {st }} \text { experimental } \\
\text { program }\end{array}$ & $\begin{array}{c}\mathbf{2}^{\text {nd }} \text { experimental } \\
\text { program }\end{array}$ \\
\hline Yield Stress "MPa" & 632 & 478 \\
\hline Tang Modulus "MPa" & 632 & 478 \\
\hline
\end{tabular}

Figure 5. Stress-Strain Curve for Steel Reinforcement

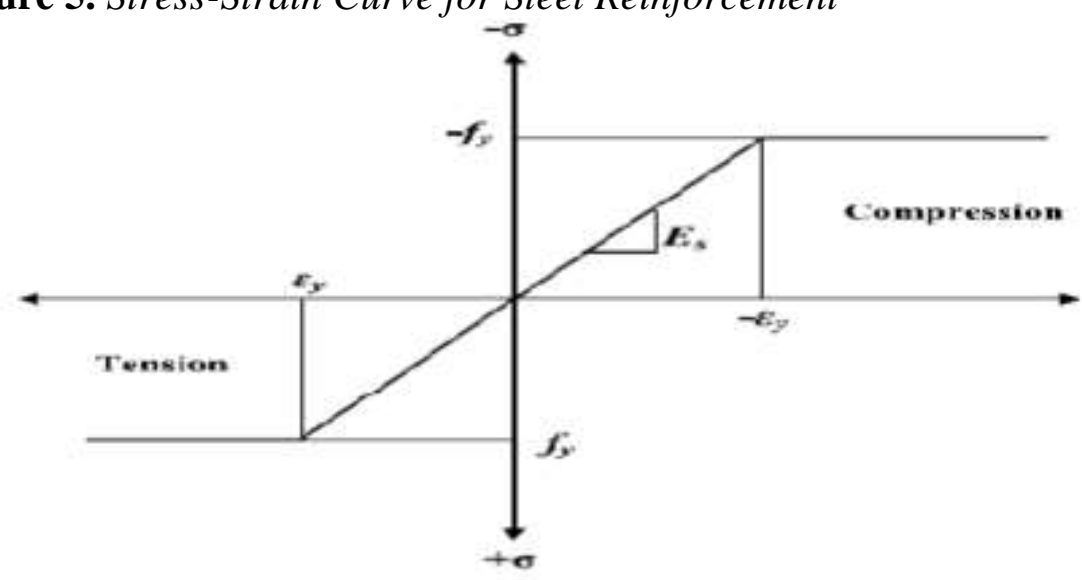

Figure 6. Link8 Element
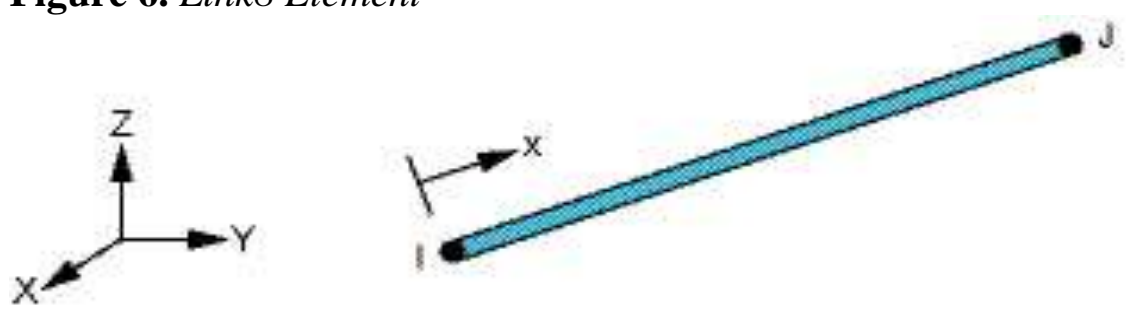


\section{Meshing \& Load Steps}

The mesh generation directly affects the accuracy of F.E. analysis results. The mesh generation method is mainly determined by the element type and shape. Perfect simulation needs highly refined meshes.

The panels are meshed with specific material characteristics by using 8node elements called Solid 65 for concrete, link 8 for reinforcement steel and solid 185 for loading plates. A dense mesh of this element type may be required in order to obtain accurate results during the analysis. ANSYS parametric design language (APDL) generates the mesh. In this method of mesh generation, the nodes are assigned to specific coordinates with ordered numbering. Then, meshed elements are formed after the nodes are joined together. The accuracy of the model, including objectivity issues related to mesh geometry and size, is demonstrated through several mesh sensitive studies, which were performed to select the optimum mesh sizes. In the models of first experimental program, the elements have a length of $50 \mathrm{~mm}$. Elements have a length of $25 \mathrm{~mm}$ in the second experimental program. In the specimen named I-L in the first experimental program, there are 4620 nodes in the model, which are connected together to form 4068 elements as shown in Figure 7. Specimen named I-S in the first experimental program, there are 5000 nodes in the model, which are connected together to form 4464 elements. Concerning the second experimental program, there are 2750 nodes in the model, which are connected together to form 2170 elements.

Figure 7. Meshed Elements

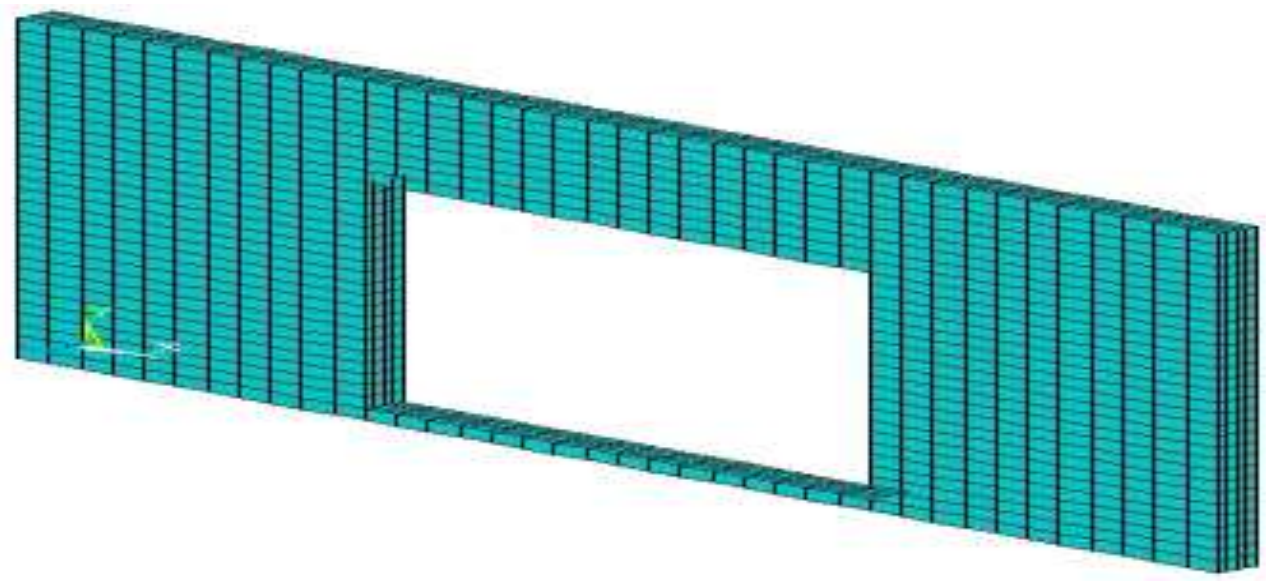

Automatic time stepping was used to solve the FE model with a specific number of substeps (1000) depending on the material properties, the value of loads and element density. In order to carry out a load-displacement curve based on non-linear analysis in ANSYS, the load should be broken into a series of load increments by defining number of load steps (185) in the first experimental program and (60) in the second experimental program, increment in load to be applied in each step and maximum load to be applied. The model must be always checked back to determine the exact load step at which the wall failed. 


\section{Loading and Boundary Condition}

Hinged connections at the top and bottom boundaries of the specimen and clamped side edges, which had to be sufficiently rigid to stop immoderate outof-plane deformations. Top edge is restrained in $\mathrm{x}$ and $\mathrm{z}$ directions along the wall length and released in y direction which is the loading direction. Bottom edge is restrained in $\mathrm{x}, \mathrm{y}$ and $\mathrm{z}$ directions along the wall length. Side edges are restrained in $\mathrm{x}$ and $\mathrm{z}$ directions along the wall height in the first experimental program but released in all directions in the second experimental program. In order to simulate what happens in the laboratory properly, an axially uniformly distributed load is applied in the F.E.M. along the wall length with a small eccentricity at both of upper and lower end (one sixth of the wall thickness) to emulate influences of defects that happen in ordinary construction practices as presented in Figure 8. In the first experimental program, the model is axially loaded by distributed load of $5000 \mathrm{kN}$ by applying pressure $185 \mathrm{Mpa}$ along the wall length and $15 \mathrm{~mm}$ width. That load almost simulates the actual loading process developed in the laboratory as the wall loaded by four hydraulic jacks, each with a most extreme limit of $1400 \mathrm{kN}$. These jacks were connected together to apply a uniformly distributed load, with controlled total force along the wall length. In the second experimental program, the model is axially loaded by distributed load of $300 \mathrm{kN}$ by applying pressure $60 \mathrm{Mpa}$ along the wall length and $12.5 \mathrm{~mm}$ width. That load almost simulates the actual loading process developed in the laboratory as the wall loaded by one hydraulic jack with a maximum capacity of $300 \mathrm{kN}$. When the model also has been loaded with different loads more than the expected failure load, it is found that the model failed at the same failure load, which ensures the F.E. model accuracy.

\section{Figure 8. Applied Load}

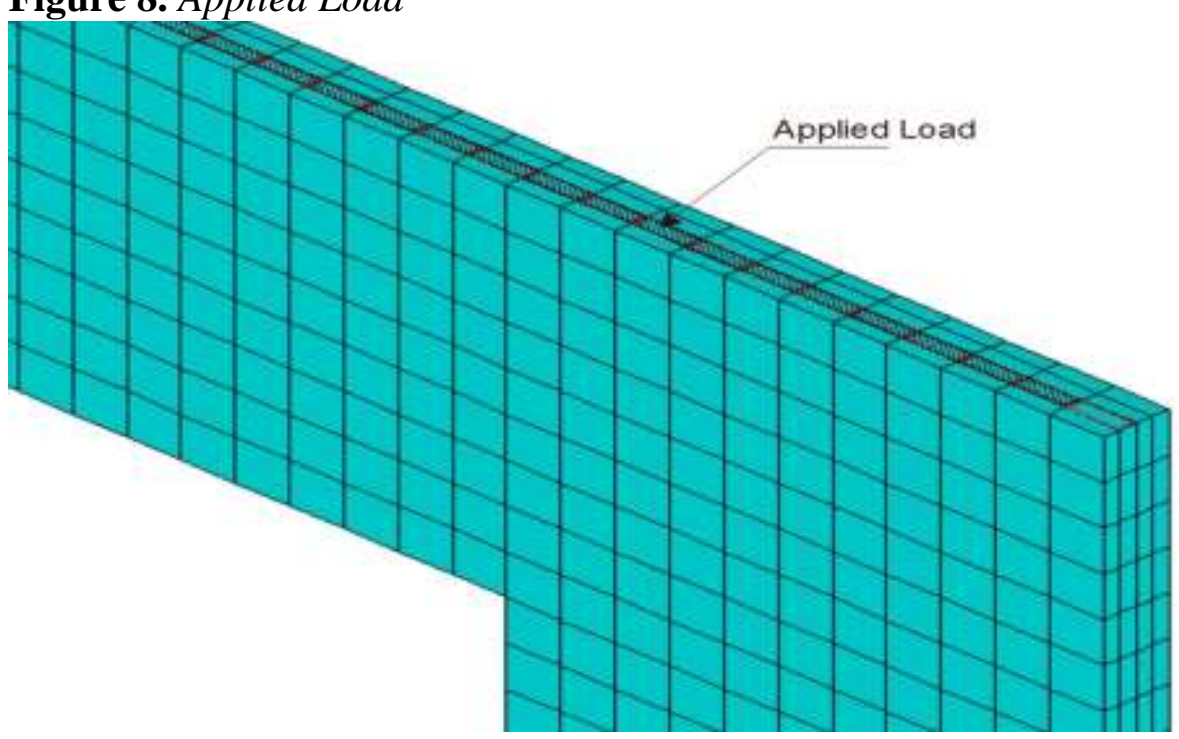




\section{Failure Criteria}

In this research, failure is considered when steel reinforcement yields followed by severe cracking of concrete. This initiates a large disturbance to the FE simulation and a major difficulty to the solution algorithm. This in turn leads to termination in the FE simulation due to a divergence. Divergence in the FE solution corresponds with an extremely large deflection, surpassing the displacement limitation of the ANSYS software.

\section{Model Verification}

F.E. modeling approach has been conducted and verified with two experimental programs of three different specimens conducted by Cosmin Popescu et al. (2016) and Mohammed et al. (2010). After verification, a parametric study is applied to investigate the effect of opening size, shape, orientation, aspect ratio, position with different R.C. wall thicknesses.

\section{Verification of First Experimental Program}

\section{$\underline{\text { Verification for Load versus Deformation Curve }}$}

The validity of the proposed material constitutive models for steel and concrete were verified by comparing their predictions with experimental data conducted from testing reinforced concrete shear wall $(1800 \mathrm{~mm}$ long, $1350 \mathrm{~mm}$ tall and $60 \mathrm{~mm}$ thick and has a symmetric opening $(900 \mathrm{~mm} \times 1050 \mathrm{~mm})$ which named I-L. The results of the verification study, Figure 9, demonstrated that the F.E. model fitted with the experimental results of the reference wall. The measured maximum capacity and corresponding out of plane displacement in the reference wall were $1180 \mathrm{kN}$ and $12 \mathrm{~mm}$, respectively. On the other hand, the F.E. predictions obtained for maximum capacity and corresponding out of plane displacement were $1240 \mathrm{kN}$ and $12.9 \mathrm{~mm}$, respectively.

Another specimen has been conducted for verification, which has a symmetric opening $(450 \mathrm{~mm} \times 1050 \mathrm{~mm})$ and named I-S. The results shown in Figure 9 demonstrated that the F.E. model fitted with acceptable accuracy the experimental results of the reference wall. The measured maximum capacity and corresponding out of plane displacement in the reference wall were $1500 \mathrm{kN}$ and $15.5 \mathrm{~mm}$, respectively. On the other hand, the F.E. predictions obtained for maximum capacity and corresponding out of plane displacement were $1780 \mathrm{kN}$ and $13 \mathrm{~mm}$, respectively. The experimental and F.E. failure loads and out of plane displacement capacities are presented in Table 4. 
Table 4. F.E. and Experimental Results

\begin{tabular}{|c|c|c|c|c|c|c|}
\hline \multirow[t]{2}{*}{ Serial } & \multicolumn{3}{|c|}{$\begin{array}{l}\text { Ultimate load, Pu } \\
(\mathbf{k N})\end{array}$} & \multicolumn{3}{|c|}{$\begin{array}{c}\text { Out of plane displacement } \\
(\mathbf{m m})\end{array}$} \\
\hline & Anal. & Exp. & Accuracy \% & Anal. & Exp. & Accuracy \% \\
\hline $\mathrm{I}-\mathrm{L}$ & 1240 & 1180 & 5.1 & 12.9 & 12 & 7.5 \\
\hline $\mathrm{I}-\mathrm{S}$ & 1605 & 1500 & 7.0 & 15.6 & 15.5 & 0.64 \\
\hline
\end{tabular}

Figure 9. Exp. and F.E. Results for I-L \& I-S Specimens
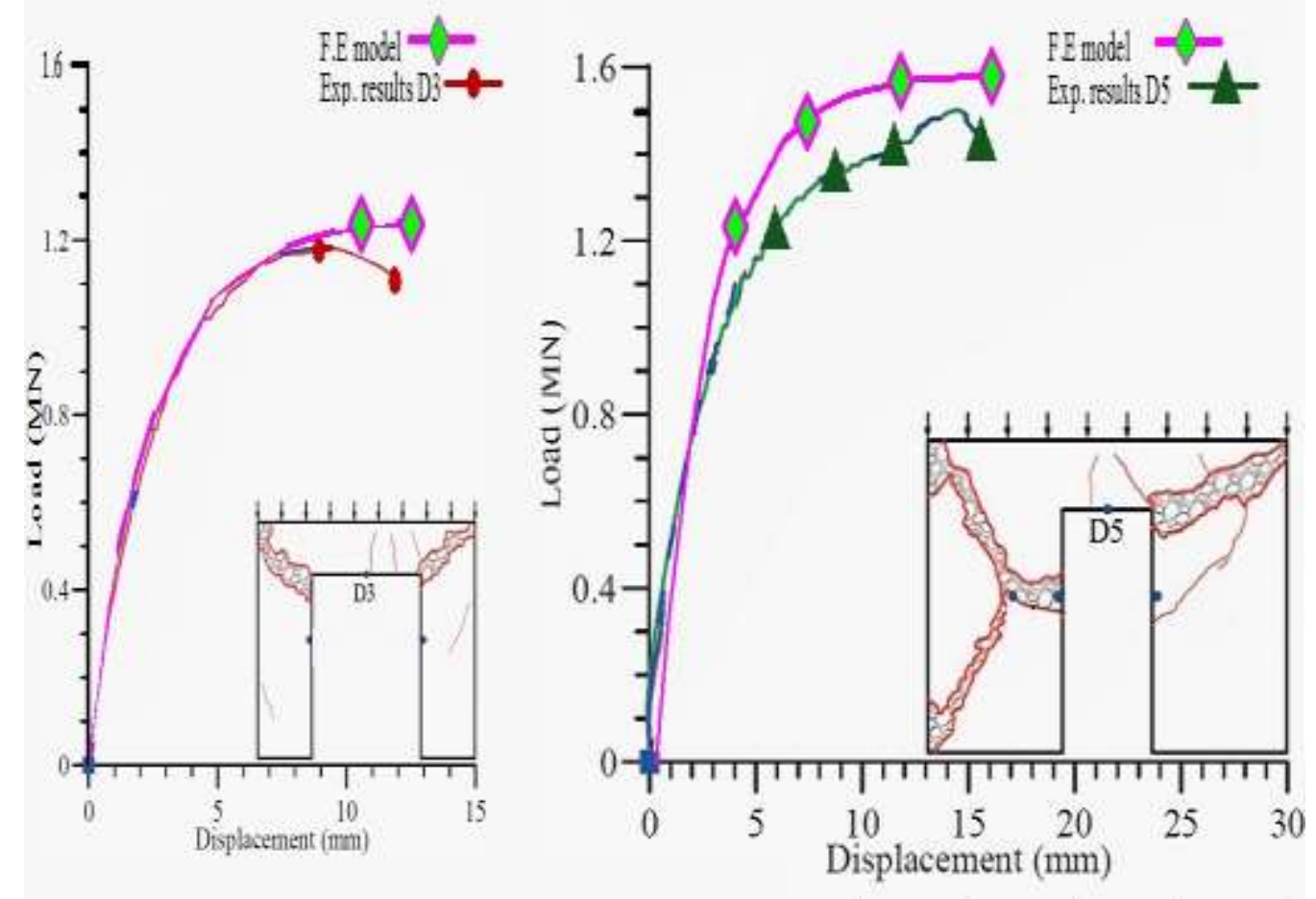

$\underline{\text { Crack Pattern and Failure Mode }}$

The specimen I-L failed in a mode of deflection in a single curvature with a maximum deflection occurring near the middle of the wall panel as shown in Figure 10. Crack Propagation is shown in Figure 11. The brittle failure in the wall caused by crushing of concrete with spalling and reinforcement buckling along the line between the opening corner and wall corner of one pier which leads to the failure of the wall panel as illustrated in Figure 12. Comparing the crack pattern of sample specimen at failure predicted numerically to that obtained from the experiment in Figure 12, there is a good correlation between the experimental and F.E. crack patterns. 
Figure 10. Deformed Shape for I-L

Figure 11. Crack Propagation for I-L
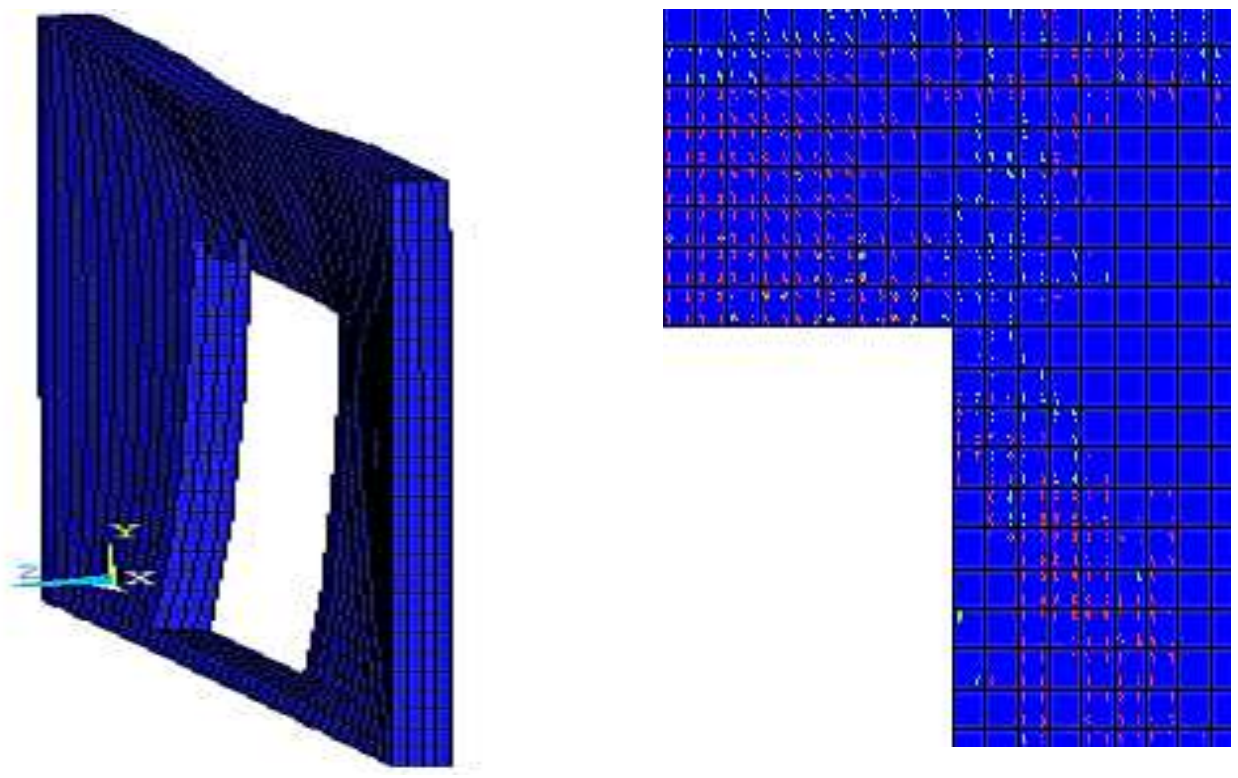

Figure 12. Cracks in Experimental Specimen for I-L

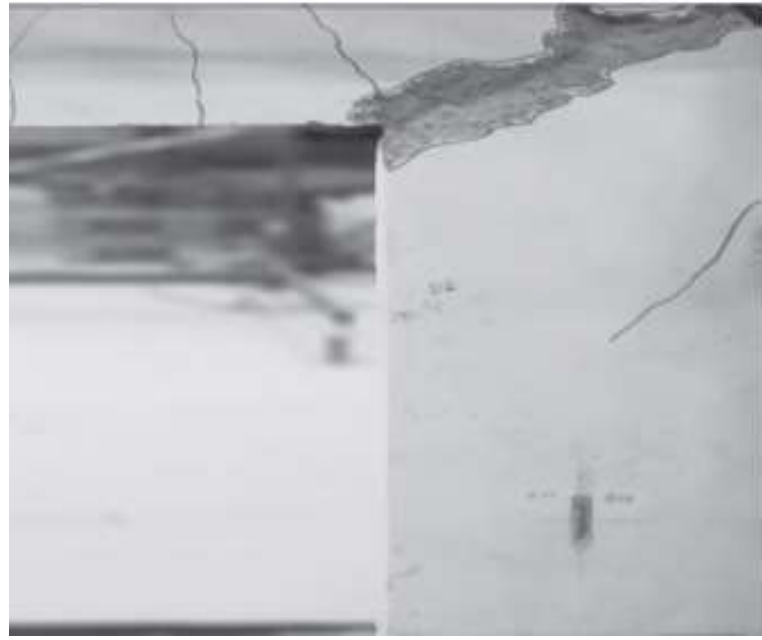

The specimen I-S failed in a mode of deflection in a single curvature with a maximum deflection occurring near the middle of the wall panel as shown in Figure 13. Cracks opened along the line between the corner of the wall and opening corner and these cracks continued to widen when several other cracks around the same location began to grow. The brittle failure in the wall caused by crushing of concrete with spalling and reinforcement buckling along the line between the opening corner and wall corner of one pier (Figure 14). Comparing the crack pattern of sample specimen at failure predicted numerically to that obtained from the experiment in Figure 15, there is a good correlation between the experimental and F.E. crack patterns. 
Figure 13. Deformed Shape for I-S

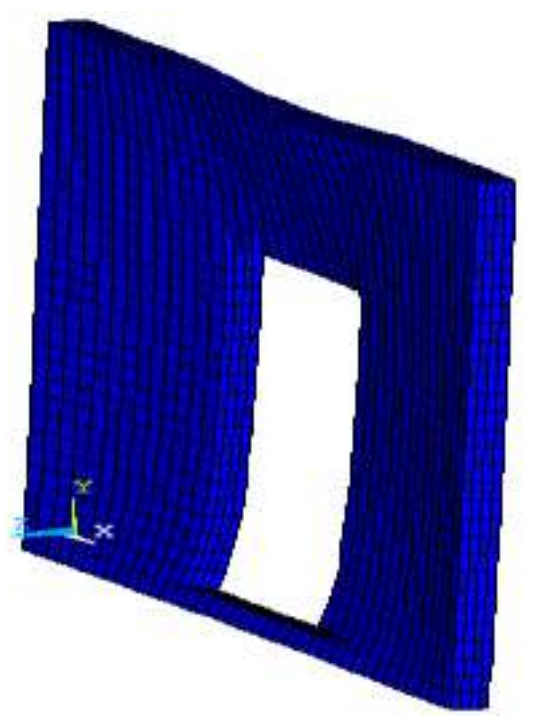

Figure 14. Crack Propagation for I-S

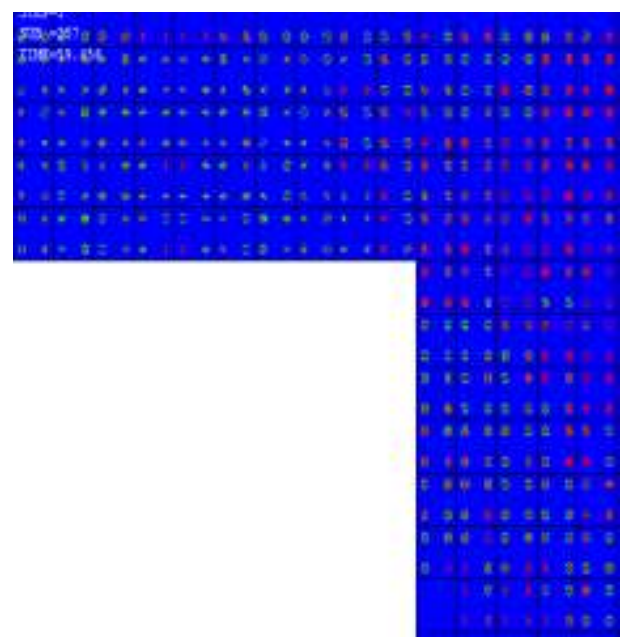

Figure 15. Cracks in Experimental Specimen for I- $S$

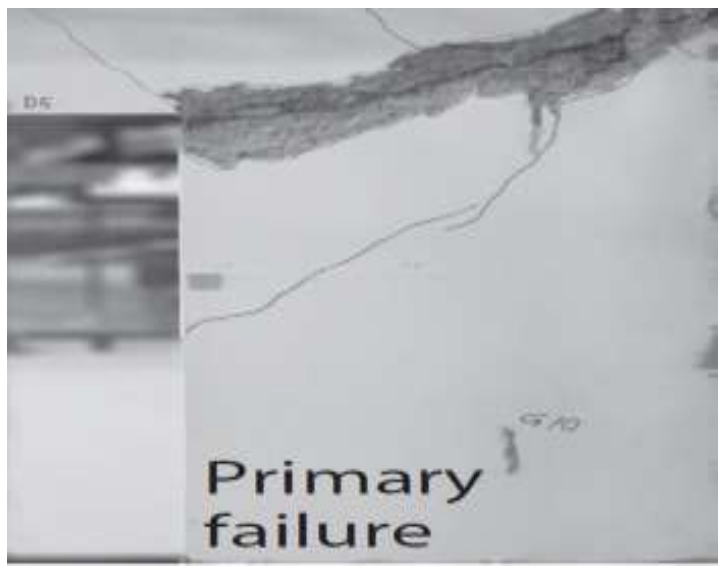

Verification for Second Experimental Program

\section{Verification for Load Capacity}

Proposed material constitutive models for steel and concrete were verified by comparing their predictions with another experimental data conducted from testing reinforced concrete shear wall (Mohammed et al. 2010). The reference wall dimensions were $(400 \mathrm{~mm}$ long, $800 \mathrm{~mm}$ tall and $50 \mathrm{~mm}$ thick and has a symmetric opening $(240 \mathrm{~mm} \times 135 \mathrm{~mm})$ which named WO2 as illustrated in Figure 3. The results of the verification study demonstrated that the F.E. model fitted with the experimental results of the reference wall. The measured maximum capacity in the reference wall was $203.8 \mathrm{kN}$. On the other hand, the F.E. predictions obtained for maximum capacity was $175.12 \mathrm{kN}$ with $16.4 \%$ variation. 


\section{$\underline{\text { Crack Pattern and Failure Mode }}$}

The specimen WO2 fails in a mode of deflection in a single curvature with a maximum deflection happening close to the middle of the wall panel as illustrated in Figure 16. The cracks begin from the center of the opening, parallel with the loading direction towards the applied loads. Followed by that is a crack from the center of the opening, parallel with the loading direction towards the bottom of the wall panel. Other than that, the cracks also happened near the middle of the wall panel, orthogonal to the loading direction, which causes the failure of the wall panel as appeared in Figure 17. Comparing the crack pattern of sample specimen at failure predicted numerically to that obtained from the experiment in Figure 18, there is a good correlation between the experimental and F.E. crack patterns.

Figure 16. Deformed Shape

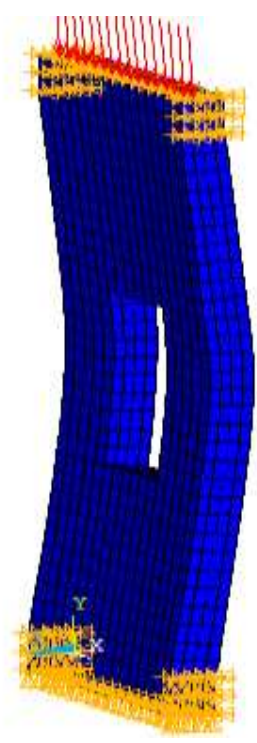

Figure 17. Crack Propagation

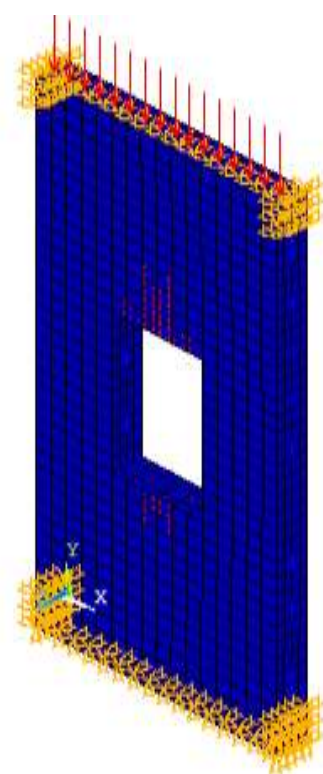

At Load 70kN

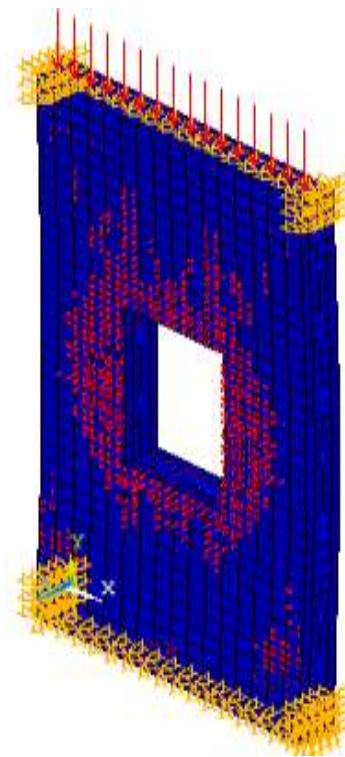

At Load $154 \mathrm{kN}$

Figure 18. Cracks in Experimental Specimen

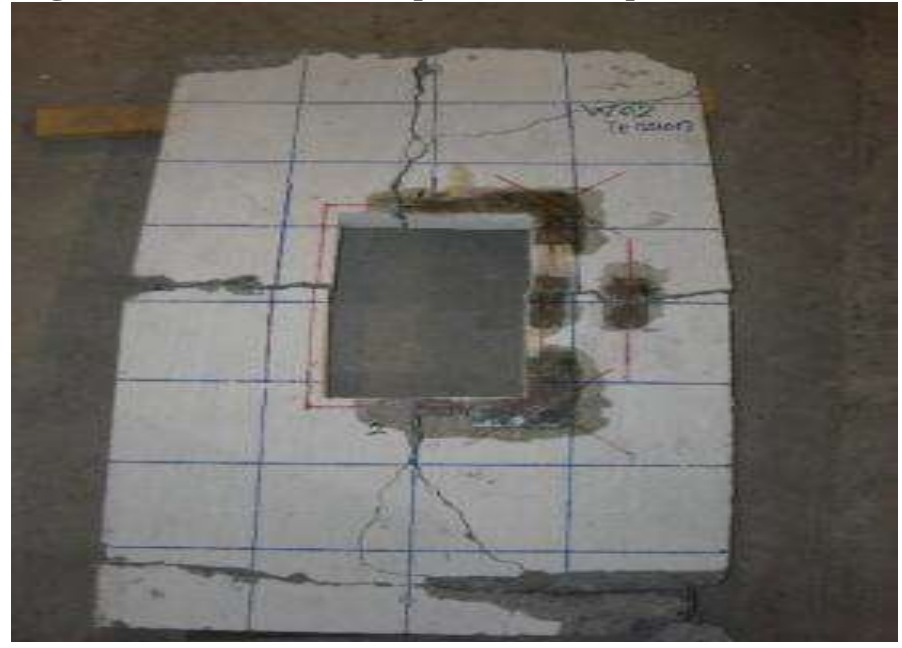


Failure mode in the F.E. models fitted with the experimental results of the reference walls, which confirms the capability of the F.E. models to accurately predict the load capacity of other models of shear walls and simulate the nonlinear structural behavior of opened shear walls to examine a larger domain of parameters instead of laboratory testing, which is expensive, timeconsuming and labor-dense. After verification of the finite element method with the proposed reference models, several arrangements of openings with a variety of dimensions were created in different shapes in the reference wall model to examine the impacts of openings.

\section{Parametric Study}

\section{Effect of Opening Shape}

Based on the F.E. study carried out on four shapes with the same average opening size and position, it is clearly seen that the opening shape has significant impact on the axial capacity values at failure stage. The square shape has the lowest carrying capacity then the circular shape is much higher and the maximum axial load capacity is related to R.C wall with vertical rectangle direction opening. As shown in Table 5, it can be noticed that for a constant average value of opening size $15.9 \%$ of the total wall area, which located in the middle, the lowest ultimate load is recorded at square shape, which is $1630.8 \mathrm{kN}$, then the circular shape with $1695.6 \mathrm{kN}$. Meanwhile, the ultimate load of wall with vertical rectangle direction opening reaches $2155.68 \mathrm{kN}$ which is slightly lower than the solid wall capacity by $8.8 \%$. Therefore, the highest load capacity is related to vertical rectangle direction and these findings indicate that the effect of changing the opening shape should not be ignored. The main reason is that the loaded cross section area at opening section in the R.C wall with vertical rectangle opening is larger than those in the other shapes at the same opening section. This large area can resist higher axial load values.

Regarding the stress concentration, the presence of the openings in the panels determines the load paths and creates high stress concentrations around the opening, which encourages cracks to occur first at the corners of the opening. Therefore, the circular openings are preferred as there are no corners $\&$ concentrations, which cause lower stress values around the opening than other shapes as shown in (Figure 19). 
Table 5. Changing Opening Shape Results

\begin{tabular}{|c|c|c|c|c|c|c|c|}
\hline $\begin{array}{c}\text { Shape } \\
\text { Sr. }\end{array}$ & $\begin{array}{c}\text { Opening } \\
\text { Shape }\end{array}$ & $\begin{array}{c}\text { Vertical } \\
\text { dim. (m) }\end{array}$ & $\begin{array}{c}\text { Horizontal } \\
\text { dim. (m) }\end{array}$ & $\begin{array}{c}\text { Average } \\
\text { Opening } \\
\text { Area \% }\end{array}$ & $\begin{array}{c}\text { Load } \\
\text { (kN) }\end{array}$ & Shape & $\begin{array}{c}\text { Capacity } \\
\text { reduction } \\
\text { than solid } \\
\text { wall \% }\end{array}$ \\
\hline $\begin{array}{c}\text { Solid } \\
\text { wall }\end{array}$ & $\begin{array}{c}\text { No } \\
\text { opening }\end{array}$ & - & - & - & 2363 & - & - \\
\hline 1 & Rectangle & 1 & 0.4 & $15.9 \%$ & 2155.7 & & $8.8 \%$ \\
\hline 2 & Circular & Dia. $=$ & 0.7 & $15.9 \%$ & 1695.6 & & $28.2 \%$ \\
\hline 3 & Square & 0.6 & 0.6 & $15.9 \%$ & 1630.8 & & $31 \%$ \\
\hline
\end{tabular}

Figure 19. Stress Concentration in Different Shapes

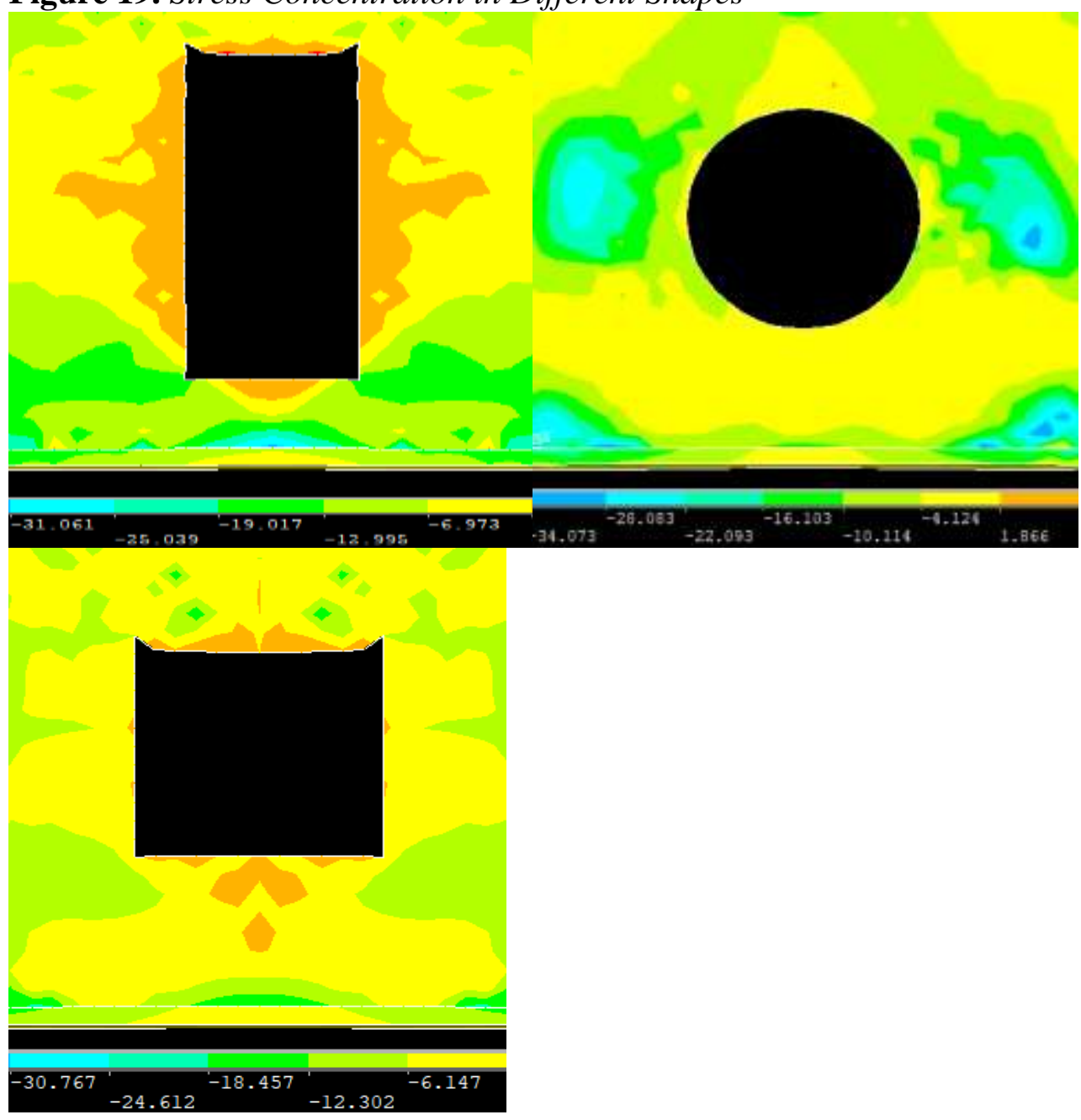




\section{Effect of Opening Orientation}

F.E. study's findings conducted that changing rectangle orientation has considerable effects on the axial capacity. The F.E. study is carried out on two different groups in terms of aspect ratio. Both of the groups have the same size and locate in the middle of the wall. The opening orientation is varying in the same group from horizontal direction to vertical direction and opening area is constant for both of groups (10\% of the total wall area). Results of Groups G1 (aspect ratio $=1.5)$ and G2 (aspect ratio $=6$ ) were analyzed to demonstrate the effect of opening orientation on RC walls behavior. The enhancement in axial capacity increases when the rectangular opening is in vertical direction because the loaded cross section area at the opening section in the R.C wall with vertical rectangle opening is larger than the loaded cross section area in the R.C wall with horizontal rectangle opening at the same opening section as shown in Table 6. When the solid wall axial capacity compared with G1 rectangular opening in vertical direction, it can be noticed that the ultimate axial load value decreases by $1 \%$ unlike the horizontal rectangle direction that records $1719.9 \mathrm{kN}$ with $27.2 \%$ reduction. G2 follows the same manner of $\mathrm{G} 1$ as vertical rectangular direction opening ultimate axial load decreases by $7.3 \%$ counter to the horizontal rectangle direction, which records $772.2 \mathrm{kN}$ with $67.3 \%$ reduction. It can be also noticed that when the aspect ratio decreases, the difference in ultimate load value between the two shapes decreases. According to the table, in G1, the difference in ultimate load value was about $621 \mathrm{kN}$. On the other hand, the aspect ratio was 6 in G2 and that significant change reflected in difference in ultimate load value which was $1418.6 \mathrm{kN}$. In addition, it can be seen that when rectangular opening is in vertical direction, the out of plane displacement values increase. The out of plane displacement here defines and indicates the ductility. When the out of plane displacement value increases, the ductility of the R.C. wall increases. As shown in Table 6, it can be noticed that for $\mathrm{G} 1$ and $\mathrm{G} 2$, the out of plane displacement for vertical rectangle direction are $20.01 \& 15.72 \mathrm{~mm}$, which are more than horizontal rectangle direction values 16.23 and $4.8 \mathrm{~mm}$ respectively. These displacement values indicate that rotation from horizontal rectangle direction to vertical rectangle direction increases the wall ductility. It is obviously concluded that the changing the opening orientation has considerable impact on the wall ductility and the axial capacity values. 
Table 6. Changing Opening Orientation Results

\begin{tabular}{|c|c|c|c|c|c|c|c|}
\hline Group & $\begin{array}{l}\text { Ver. } \\
\text { Dim. } \\
\text { (m) }\end{array}$ & $\begin{array}{c}\text { Hor. } \\
\text { Dim. (m) }\end{array}$ & $\begin{array}{c}\text { Aspect } \\
\text { ratio }\end{array}$ & Orientation & $\begin{array}{c}\text { Load } \\
\text { kN }\end{array}$ & $\begin{array}{c}\text { Capacity } \\
\text { reduction } \\
\text { than solid } \\
\text { wall \% }\end{array}$ & $\begin{array}{c}\begin{array}{c}\text { Out of } \\
\text { plane } \\
\text { Dis. } \\
(\mathrm{mm})\end{array} \\
\end{array}$ \\
\hline Solid & $\overline{-}$ & $\overline{-}$ & $\overline{-}$ & $\bar{Z}$ & 2363 & $\bar{Z}$ & 22.5 \\
\hline \multirow{2}{*}{ G1 } & 0.6 & 0.4 & \multirow{2}{*}{1.50} & & 2340.9 & $1 \%$ & 20.01 \\
\hline & 0.4 & 0.6 & & & 1719.9 & $27.2 \%$ & 16.23 \\
\hline \multirow{2}{*}{ G2 } & 1.2 & 0.2 & \multirow{2}{*}{6.00} & & 2350.4 & $0.5 \%$ & 15.72 \\
\hline & 0.2 & 1.2 & & & 772.2 & $67.3 \%$ & 4.80 \\
\hline
\end{tabular}

\section{Effect of Opening Aspect Ratio}

FE models illustrated that opening aspect ratio has significant impact on the axial load capacity of R.C walls. From Figure 20, it can be seen that when aspect ratio of middle horizontal rectangle direction opening is increased, the axial load capacity of the shear wall decreases because of the reduction in the resisting cross section area in the R.C. wall. While studying opening sizes $10.97 \%, 15.14 \%$ and $19.34 \%$ of the total wall area, it can be noticed that the reduction percentage in the solid wall ultimate load of aspect ratio 1 is (29\%) which shows better results when compared to aspect ratio 2 (43.2\%). The reduction percentage at aspect ratio $3(58.4 \%)$ is lower than aspect ratio 4 which recorded the highest reduction percentage in the solid wall ultimate load (65\%). 
Figure 20. Aspect Ratio versus Capacity Diagrams
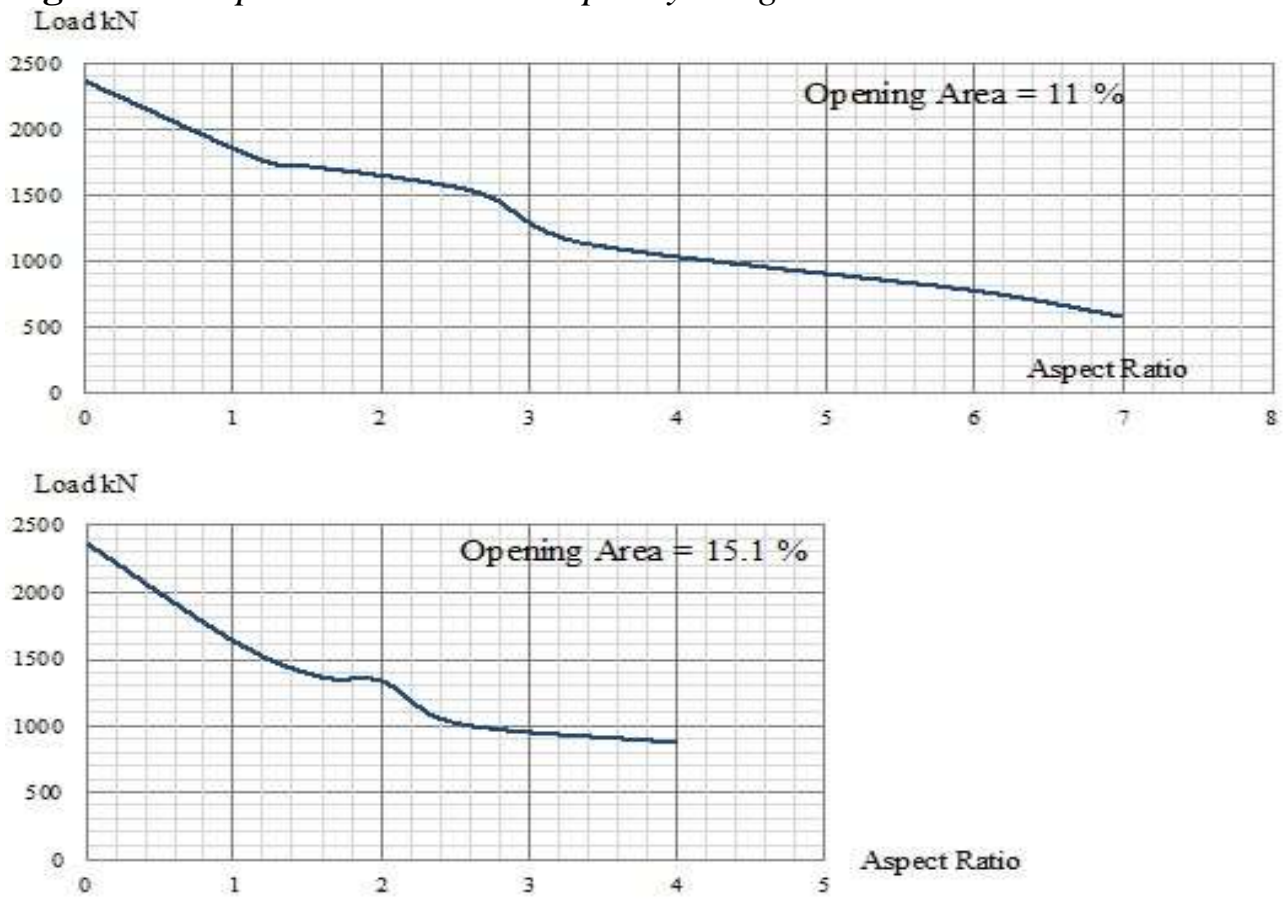

Load $k N$

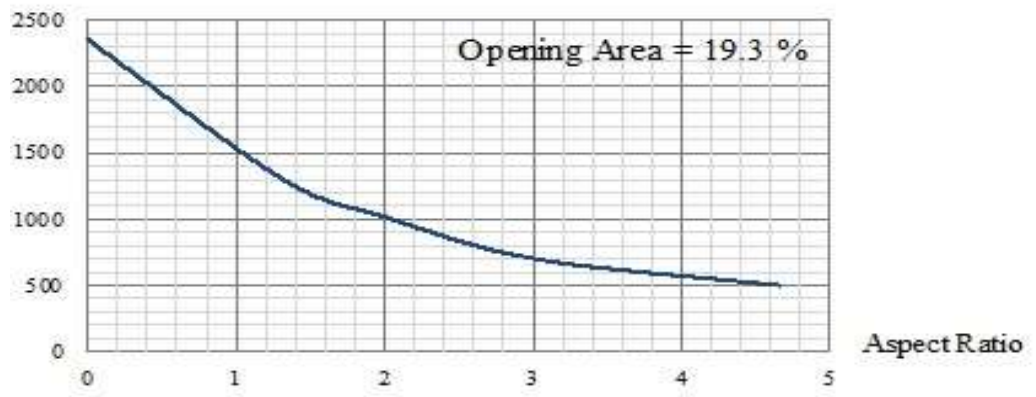

\section{Effect of Opening Position}

Figure 21 shows the positions of openings in the R.C. wall. The FE models in Table 7 conducted that the highest axial load capacity values at openings located at bottom of the shear wall because this position is away from the loaded edge and the axial load path. Then followed by lower load capacity values are recorded for the models with openings in the middle of the shear walls. In contrast, while the openings located at the top of the shear wall, the ultimate axial load value decreased sharply to be the lowest.

In addition, it can be noticed that when opening is shifted from the middle to edges and corners, the ultimate axial load values become lower than those in the middle. For example, in Table 7, it can be seen that for a constant value of opening size $(6.58 \%$ of the total wall area) and constant shape (square), the ultimate load of position 2 is $2281.5 \mathrm{kN}$ which shows better results when compared to position 3 and slightly lower than position 1 which recorded the 
highest axial capacity (2334.15) and the lowest reduction percentage from the solid wall capacity $(1.22 \%)$.

Figure 21. Positions of Opening in R.C Wall

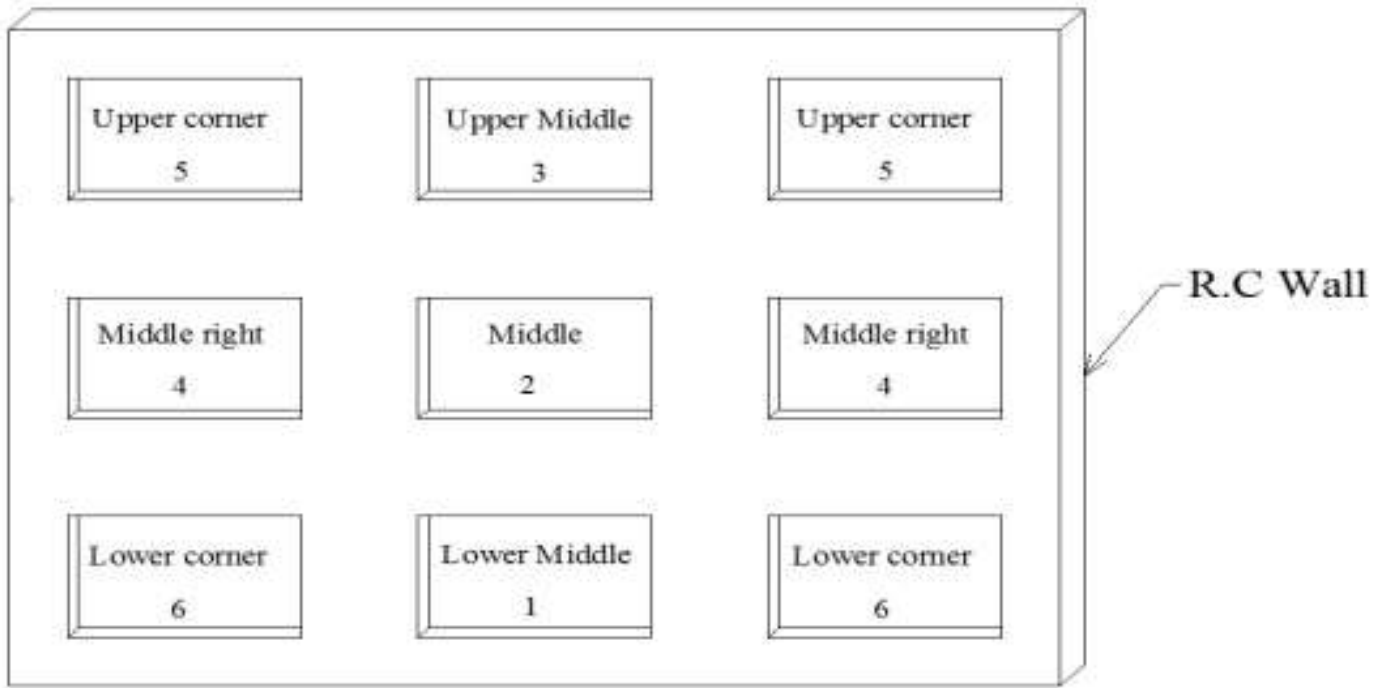

Shifting the opening position from position 1 to position 4 has displayed decreasing in the ultimate axial load value by $9 \%$. The reduction in capacity from solid wall rose up from $1.22 \%$ to $12.13 \%$. Another noticeable feature is that the highest out of plane displacement is corresponded to position 2 , which is $20.05 \mathrm{~mm}$.

This leads us to believe that the best opening position in the shear wall in terms of axial load capacity is at the lower side in the middle (position 1) and in terms of ductility is at exact middle of the shear wall (position 2).

Table 7. Changing Opening Position Results

\begin{tabular}{|c|c|c|c|c|c|c|}
\hline $\begin{array}{c}\text { Position } \\
\text { Sr. }\end{array}$ & Position & $\begin{array}{c}\text { Ver. } \\
\text { Dim. } \\
(\mathbf{m})\end{array}$ & $\begin{array}{c}\text { Hor. Dim. } \\
(\mathbf{m})\end{array}$ & $\begin{array}{c}\text { Load } \\
\mathbf{k N}\end{array}$ & $\begin{array}{c}\text { Capacity } \\
\text { reduction } \\
\text { than solid } \\
\text { wall \% }\end{array}$ & $\begin{array}{c}\text { Out of } \\
\text { plane } \\
\text { Dis. } \\
(\mathbf{m m})\end{array}$ \\
\hline Solid & - & - & - & 2363 & - & 22 \\
\hline 1 & $\begin{array}{c}\text { Lower } \\
\text { Middle }\end{array}$ & 0.4 & 0.4 & 2334.2 & $1.22 \%$ & 10.73 \\
\hline 2 & Middle & 0.4 & 0.4 & 2281.5 & $3.45 \%$ & 20.05 \\
\hline 3 & $\begin{array}{c}\text { Upper } \\
\text { Middle }\end{array}$ & 0.4 & 0.4 & 1657.8 & $29.8 \%$ & 5.9 \\
\hline 4 & $\begin{array}{c}\text { Middle } \\
\text { Right }\end{array}$ & 0.4 & 0.4 & 2076.3 & $12.13 \%$ & 9.33 \\
\hline 5 & $\begin{array}{c}\text { Upper } \\
\text { Corner }\end{array}$ & 0.4 & 0.4 & 1117.8 & $52.7 \%$ & 9.3 \\
\hline 6 & $\begin{array}{c}\text { Lower } \\
\text { Corner }\end{array}$ & 0.4 & 0.4 & 2206.2 & $6.6 \%$ & 9.35 \\
\hline
\end{tabular}




\section{Effect of Opening Size}

Opening size is highly affecting the axial capacity of R.C wall. Figure 22 briefly summarizes results for various models, which have the four shapes (vertical rectangle direction, circular, square and horizontal rectangle direction) and the same position (middle) \& aspect ratio but have different sizes. The ultimate axial loads are presented in Figure 23 in the vertical axe and opening sizes are presented in the horizontal axe. The load-size curve indicates that minor effects on ultimate axial load are yielded for the shear wall with opening area less than $7 \%$ of the whole wall area. That almost accomplishes with guidelines provided in AS3600 (2009) and EN 1992-1-1 (2004) which state that if the walls are restrained on all sides and enclose an opening with an area less than $1 / 10$ of the total, the effects of this opening on the axial strength can be neglected. Another noticeable feature is that when openings are large enough and exceed $7 \%$ of the whole wall area, the axial load capacity of the shear wall becomes less. According to the graph, the load capacity of circular shape went down to about $84.4 \%$ from $2352 \mathrm{kN}$ to $1275.48 \mathrm{kN}$ as we move from opening size $7 \%$ to $26.2 \%$. Additionally, the opening area has extensive impact on out of plane displacement values of the shear wall as presented in table 8 for circular shape as an example. However, the out of plane displacement is reduced considerably as the opening size increases. The major conclusion that has been drawn is that small openings (size $<7 \%$ ) have negligible effect on shear wall capacity. In contrast, the larger the size of the opening, the lower is the amount of shear wall capacity and ductility.

\section{Figure 22. Load-size Relationship Curve}

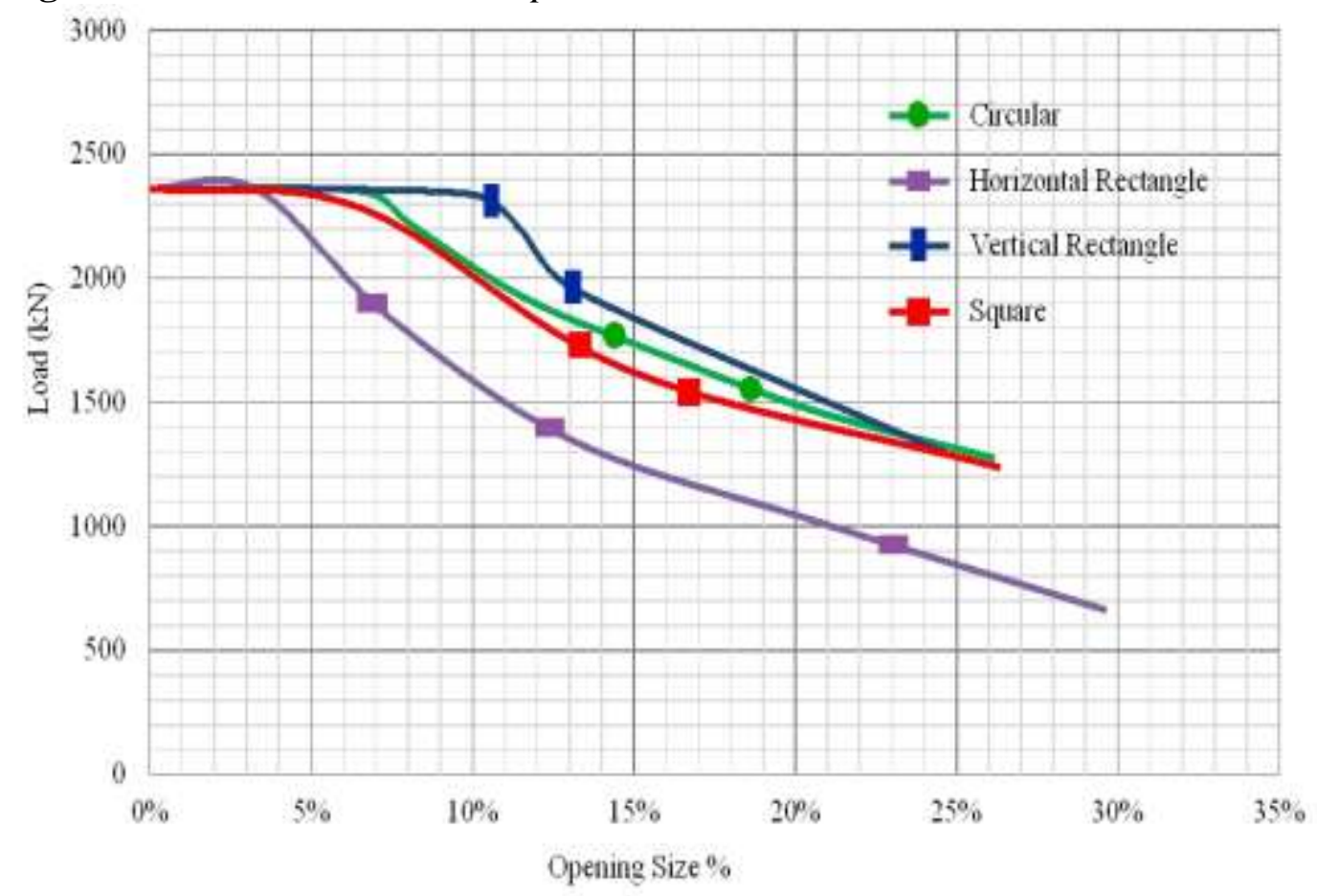


Table 8. Changing Opening Size Results

\begin{tabular}{|c|c|c|c|c|c|}
\hline Shape & $\begin{array}{c}\text { Opening } \\
\text { Position }\end{array}$ & $\begin{array}{c}\text { Opening } \\
\text { Area \% }\end{array}$ & $\begin{array}{c}\text { Load } \\
\text { kN }\end{array}$ & $\begin{array}{c}\text { Capacity } \\
\text { reduction } \\
\text { than solid } \\
\text { wall \% }\end{array}$ & $\begin{array}{c}\text { Out of plane } \\
\text { displacement } \\
\text { (mm) }\end{array}$ \\
\hline Solid & & $0.00 \%$ & 2363 & $0.00 \%$ & 21 \\
\hline $\begin{array}{c}\text { Circular } \\
(\text { Dia. }=0.45 \mathrm{~m})\end{array}$ & Middle & $6.54 \%$ & 2351.97 & $0.47 \%$ & 17.3 \\
\hline $\begin{array}{c}\text { Circular } \\
(\text { Dia. }=0.50 \mathrm{~m})\end{array}$ & Middle & $8.08 \%$ & 2219.4 & $6.08 \%$ & 15.49 \\
\hline $\begin{array}{c}\text { Circular } \\
(\text { Dia. }=0.60 \mathrm{~m})\end{array}$ & Middle & $11.63 \%$ & 1920.78 & $18.71 \%$ & 15.23 \\
\hline $\begin{array}{c}\text { Circular } \\
(\text { Dia. }=0.70 \mathrm{~m})\end{array}$ & Middle & $15.83 \%$ & 1695.6 & $28.24 \%$ & 10.4 \\
\hline $\begin{array}{c}\text { Circular } \\
(\text { Dia. }=0.80 \mathrm{~m})\end{array}$ & Middle & $20.67 \%$ & 1463.4 & $38.07 \%$ & 8.225 \\
\hline $\begin{array}{c}\text { Circular } \\
(\text { Dia. }=0.90 \mathrm{~m})\end{array}$ & Middle & $26.17 \%$ & 1275.48 & $46.02 \%$ & 7.5 \\
\hline
\end{tabular}

\section{Effect of Shear Wall Thickness}

Figure 23. Load - Slenderness Ratio $(\lambda=H / t)$ Curve

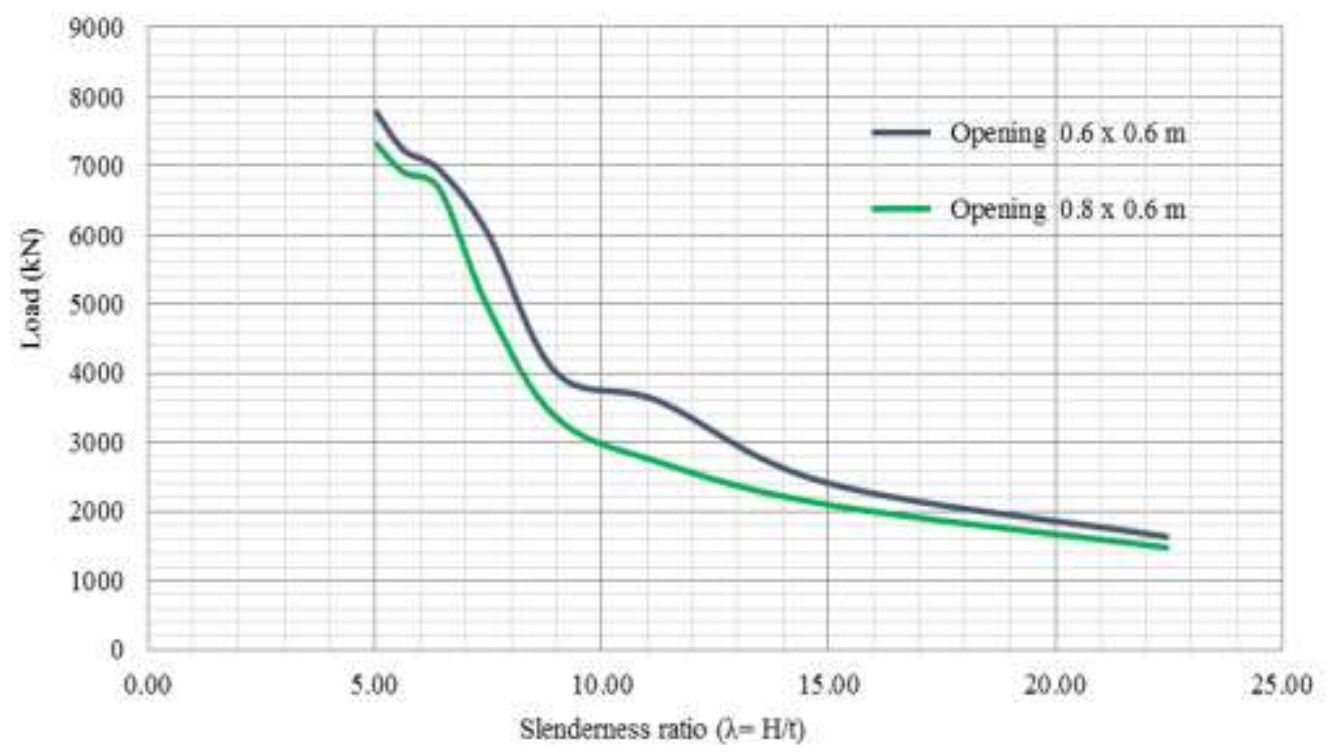

F.E. study is carried out on two different openings in terms of shape and size but both of them locate in the middle of the wall. Each opening is modeled with different wall thicknesses. Figure 23 briefly summarizes results of changing the wall thicknesses where the ultimate axial loads are shown in the vertical axe and slenderness ratio $(\lambda=\mathrm{H} / \mathrm{t})$ are shown in the horizontal axe. The load - slenderness ratio curves indicate that there is a gradual increase in ultimate axial load when slenderness ratio is higher than 10 . The graph shows a sharp increase in ultimate axial load when slenderness ratio is lower than 10 . Another noticeable feature is that when wall thicknesses are large enough, the 
out of plane displacement of the shear wall at failure becomes less and that leads to ductility reduction. According to the Table 9, the out of plane displacement for openings $14.81 \%$ \& $19.75 \%$ went down from $12.02 \mathrm{~mm}$ to $0.96 \mathrm{~mm}$ and from $8.4 \mathrm{~mm}$ to $0.95 \mathrm{~mm}$ respectively as we move from ratio 22.5 to 5. In conclusion, increasing the wall thickness has considerable effect on the axial capacity but decreasing the wall ductility.

Table 9. Changing Shear Wall Thickness for Opening $0.6 \times 0.6 \mathrm{~m} \& 0.8 \times 0.6 \mathrm{~m}$

\begin{tabular}{|c|c|c|c|c|c|}
\hline \multirow[b]{4}{*}{$\begin{array}{l}\text { Thickness } \\
\text { (m) }\end{array}$} & & \multirow{3}{*}{\multicolumn{2}{|c|}{ Opening 0.6 x $0.6 \mathrm{~m}$}} & \multirow{2}{*}{\multicolumn{2}{|c|}{ Opening 0.8 x $0.6 \mathrm{~m}$}} \\
\hline & \multirow[b]{3}{*}{$\begin{array}{c}\text { Slenderness } \\
\text { ratio }(\lambda=H / t)\end{array}$} & & & & \\
\hline & & & & \multicolumn{2}{|c|}{ Opening Size $19.75 \%$} \\
\hline & & $\begin{array}{c}\text { Load } \\
(\mathbf{k N})\end{array}$ & $\begin{array}{c}\text { Out of plane } \\
\text { Dis. } \\
(\mathrm{mm})\end{array}$ & $\begin{array}{l}\text { Load } \\
(\mathbf{k N})\end{array}$ & $\begin{array}{c}\text { Out of plane } \\
\text { Dis. } \\
(\mathrm{mm})\end{array}$ \\
\hline 0.06 & 22.50 & 1630.80 & 12.02 & 1475.01 & 8.40 \\
\hline 0.09 & 15.00 & 2408.40 & 6.65 & 2097.90 & 5.31 \\
\hline 0.12 & 11.25 & 3599.64 & 3.69 & 2717.28 & 3.15 \\
\hline 0.15 & 9.00 & 4006.80 & 3.20 & 3358.80 & 2.97 \\
\hline 0.18 & 7.50 & 6010.20 & 1.40 & 4941.00 & 1.33 \\
\hline 0.21 & 6.43 & 6939.00 & 1.00 & 6660.90 & 0.99 \\
\hline 0.24 & 5.63 & 7236.00 & 0.97 & 6912.00 & 0.95 \\
\hline 0.27 & 5.00 & 7803.00 & 0.96 & 7344.00 & 0.94 \\
\hline
\end{tabular}

\section{Current Mathematical Design Models for R.C. Walls with Rectangular and Square Openings}

Presence of openings in R.C. wall significantly decreases its ultimate load capacity in comparison to the solid wall. There is very limited information in the research literature may be due to the complex failure mechanisms of such elements. Design equations are not provided in the design codes to predict the axial strength of a concrete wall with openings. AS3600 (2009) and EN 19921-1 (2004) give a few guidelines, which express that if the walls are restrained on all sides and have an opening with a size under $1 / 10$ of the total wall area, the impacts of this opening on the axial strength can be ignored.

The below mentioned design models are improved by many attempts and include effects of area, location, dimensions and boundary condition:

\section{Saheb and Desayi Model}

Saheb and Desayi (1990) had studied the effect of one or two openings, positioned either symmetrically or asymmetrically, and combinations of window or door openings. The equation which is given underneath has been proposed to extend the usefulness of their empirical technique to represent the presence of area and position in an opening. 
$\mathrm{N}_{\mathrm{u} 0}=\left(\mathrm{k}_{1}-\mathrm{k}_{2} \alpha_{x}\right) \mathrm{N}_{u}$

eq. (1)

where $\mathrm{N}_{\mathrm{u}}$ is the ultimate load of a panel without openings. The constants $\mathrm{k}_{1}$ and $\mathrm{k}_{2}$ were obtained using curve-fitting techniques. Under one way $(\mathrm{OW})$ action this procedure yields $\mathrm{k}_{1}=1.25$ and $\mathrm{k}_{2}=1.22$, while under two way (TW) action $\mathrm{k}_{1}=1.02$ and $\mathrm{k}_{2}=1.00$. The effect of the area and position of the opening in the wall is taken into consideration via a dimensionless parameter, ${ }^{\alpha_{x}}$, defined from equation 2 and Figure 24.

$\alpha_{x x}=\frac{A_{a x}}{A_{x x}}+\frac{a}{L} \quad$ eq. (2)

where $\mathrm{A}_{0 \mathrm{x}}$ and $\mathrm{A}_{\mathrm{x}}$ represent the horizontal wall cross-sectional area of the opening (i.e. $A_{0 x}=L_{0} t$ ) and of the solid wall (i.e. $A_{x}=L t$ ), respectively. The term $\mathrm{a}^{\prime}$ is figured concurring to the following equation

$\mathrm{a}^{\prime}=\frac{0.5 L^{2} t-\mathrm{L}_{0} t \mathrm{a}_{0}}{L t-\mathrm{L}_{0} t}$

\section{Doh and Fragomeni Model}

Doh and Fragomeni (2006) proposed another set of constants for Eq. (1) based on new arrangements of tests on walls with openings under both OW and TW actions. The main difference between this model and the Saheb and Desayi model is: Demonstrate different values for the constants, based on another arrangement of experimental tests. In addition, the constants $\mathrm{k}_{1}$ and $\mathrm{k}_{2}$ were obtained using curve-fitting techniques, this time through a larger number of tests. For OW panels this yielded $\mathrm{k}_{1}=1.175$ and $\mathrm{k}_{2}=1.188$, while for TW panels $\mathrm{k}_{1}=1.004$ and $\mathrm{k}_{2}=0.933$. Both models take into consideration the area and location of an opening through the parameter ${ }^{\alpha_{x}}$, permitting a decrease in the ultimate capacity. Fragomeni et al. (2012) found that this model provides outputs in good agreement with the test results from another experimental study (Lee 2008).

\section{Guan et al. Model}

Guan et al. (2010) found that raising both the length and the height of an opening has the most considerable effect on the capacity and proposed a new model in order to take this effect into consideration. Having established a benchmark model, the authors executed a parametric study by changing the parameters that the capacity was most sensitive to. Their analysis proceeded via a nonlinear F.E. approach. In the model a three-dimensional stress state was used with elastic brittle fracture behavior for concrete in tension, and a strain hardening plasticity technique was supposed for concrete in compression. Their model is almost conformable to that proposed by Doh and Fragomeni (2006), 
the main contrast being that $\alpha_{x}$ was changed to $\alpha_{x y}$ to take the opening height into consideration.

$\alpha_{x y}=\frac{\alpha_{x x}+y \alpha_{y}}{1+y}$ where $\alpha_{y y}=\frac{A_{\Delta y}}{A_{y}}+\frac{d}{H} \quad$ eq. (4)

in which $\mathrm{A}_{0 \mathrm{y}}$ represents the vertical cross-sectional area of the opening (i.e. $\mathrm{A}_{0 \mathrm{y}}$ $=\mathrm{H}_{0} \mathrm{t}$ ), Ay represents the vertical cross-sectional area of the solid wall (i.e. $\mathrm{A}_{\mathrm{y}}$ $=\mathrm{Ht})$ and $\mathrm{d}$ represents the distance between centers of gravity $\left(\mathrm{G}_{1}\right.$ and $\left.\mathrm{G}_{3}\right)$ of the wall with and without the opening, in the vertical direction (Figure 24). $Y$ represents "the weighting ratio indicating the percentage of $\alpha_{y}$ in relation to $\alpha_{x}$, ' Using regression analysis, a new set of constants was determined; $Y=$ $0.21, \mathrm{k}_{1}=1.361$ and $\mathrm{k}_{2}=1.952$ for $\mathrm{OW}$ walls and $Y=0.40, \mathrm{k}_{1}=1.358$ and $\mathrm{k}_{2}=$ 1.795 for TW walls. It ought to be noted that this model was obtained from walls with an aspect ratio of unity and a fixed slenderness ratio (i.e. $\mathrm{k}=30$ ).

Figure 24. Geometry of a Wall with Openings (G3 = Center of Gravity of Wall with Opening, G1 = Center of Gravity of Solid Wall, G2 = Center of Gravity of Opening)

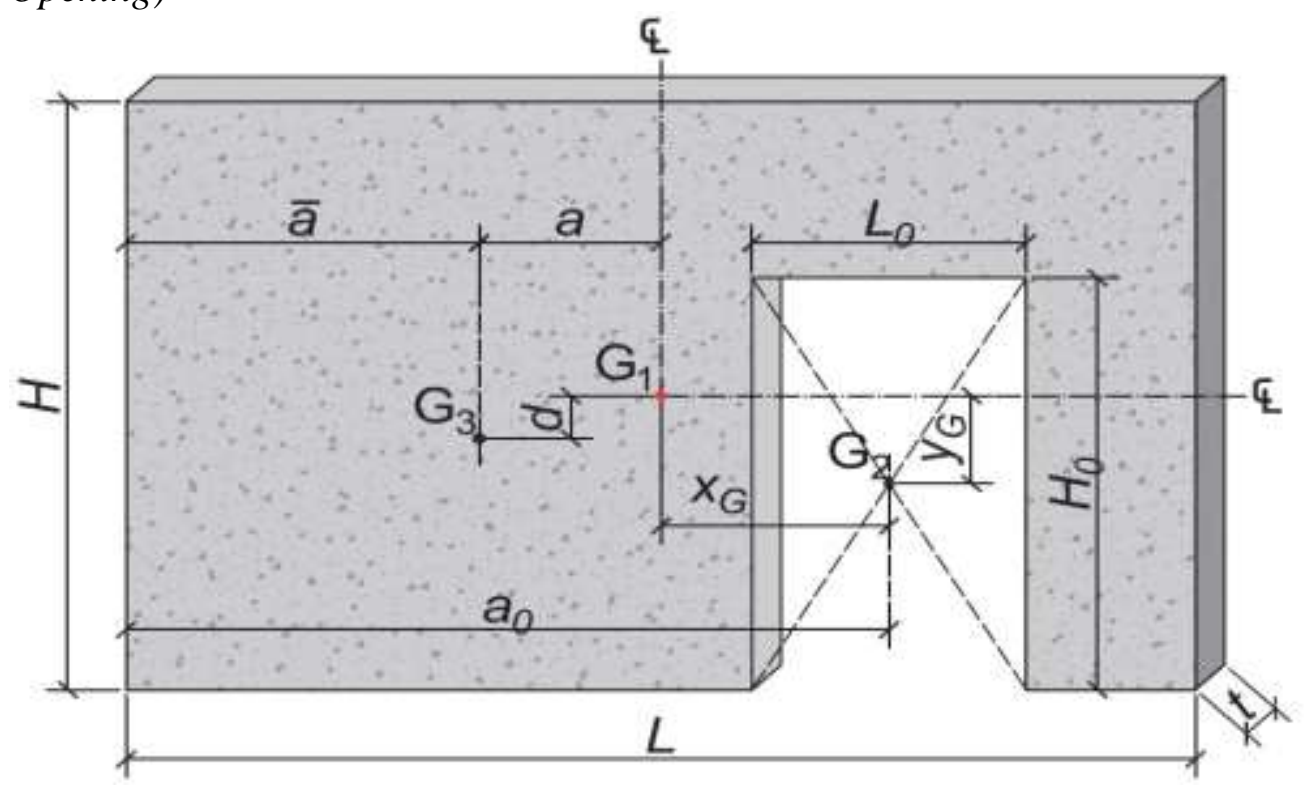

The above-mentioned researchers didn't take into considerations some important parameters which affect the accuracy of these models such as changing the thicknesses of R.C wall with opening, walls with eccentricities above $t / 6$ and the effect of circular openings on R.C. Walls. Therefore, a statistical analysis is performed on each model in turn, using all of the results conducted by the F.E. models available in order to validate the accuracy of the mathematical current design models. 


\section{Comparison between the Proposed F.E.M and the Current Mathematical Design Models for R.C. Walls with Rectangular and Square Openings}

By using the results of 38 F.E. models, Figure 25 represents the ultimate axial strength of the wall predicted by the F.E. approach versus the ultimate axial strength of the wall predicted by the investigated mathematical design models. The tested walls are assumed to be loaded axially with an eccentricity of $t / 6$. The axial capacity values for F.E. models are close to mathematical axial capacity values conducted by the three mathematical design models. According to the figure, the accuracy varies from $-20.8 \%$ to $+26 \%$. It can be seen that Saheb and Desayi model (1990) and Doh and Fragomeni model (2006) almost provide slightly higher ultimate axial loads than the proposed F.E. model. On the other hand, the ultimate axial loads predicted by Guan et al. model (2010) are approximately very close to the proposed F.E. model. Therefore, the model proposed by Guan et al. (2010) has the best performance relative to the proposed F.E. model.

Figure 25. Assessment of Ultimate Load Design Models

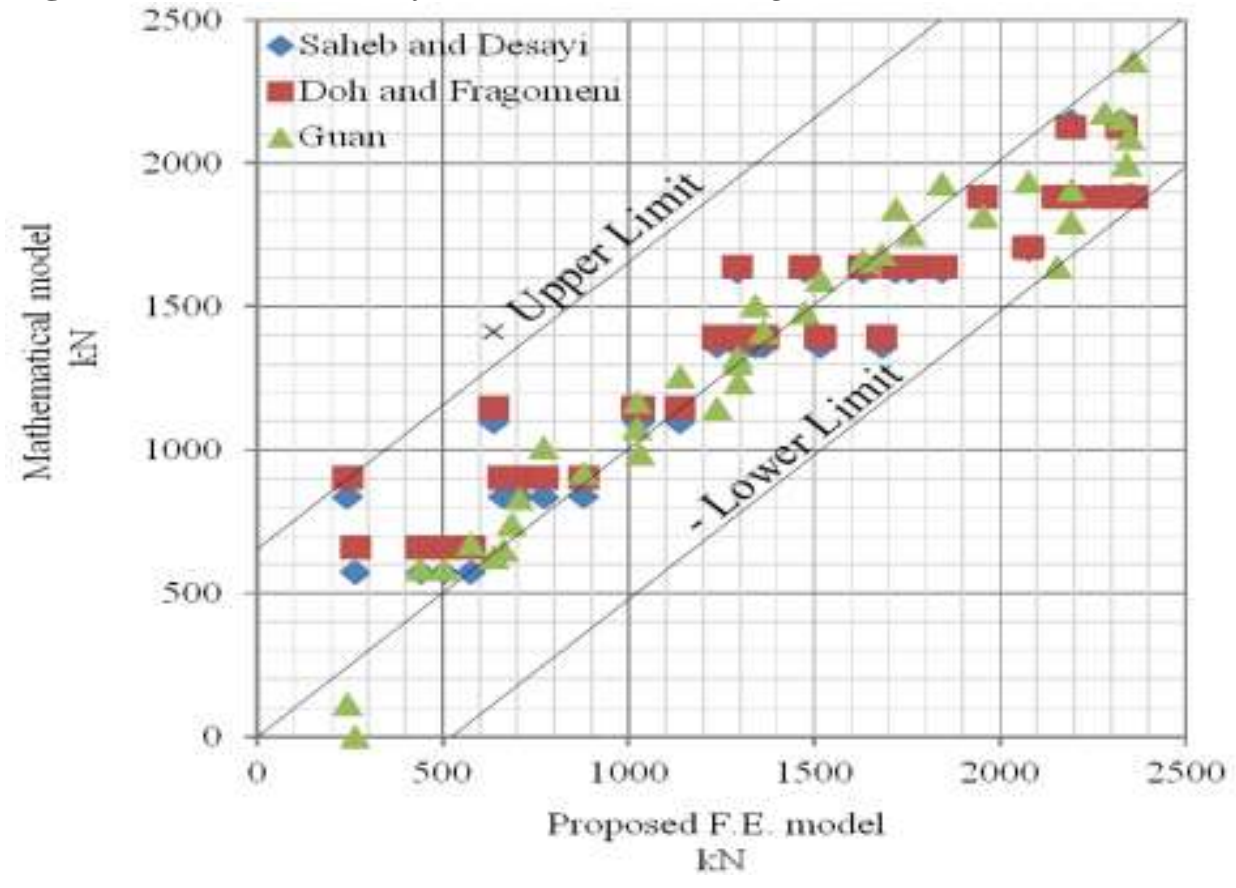

Through the statistical analysis of the proposed F.E. studies, this study indicates areas where further testing is required in order to enhance the reliability of current design models. It was found that most researches have focused on testing RC walls under $\mathrm{OW}$ and TW action, with a fixed eccentricity of $t / 6$. Therefore, more tests are required in these experimental regimes to facilitate the development of appropriate design models. Obtaining the mathematical formula of the ultimate axial strength of the R.C. wall with circular opening is studied in this research. 


\section{Proposed Model for the Ultimate Axial Strength of the R.C. Wall with Circular Opening}

Based on the findings of the F.E. approach and other studied mathematical design models, Figure 26 represents regression analysis results of 5 R.C. wall specimens with different circular openings sizes. These specimens have been tested by ANSYS up to failure and the following formula is proposed using curve-fitting technique for ultimate axial strength of walls with circular opening:

$\mathrm{N}_{\mathrm{uo}}=\mathrm{N}_{\mathrm{u}}+165606 \mathrm{P}^{3}-68518 \mathrm{P}^{2}+2438.2 \mathrm{P}$

Where

$\mathrm{N}_{\mathrm{uo}}$ : the predicted ultimate load of a R.C. wall with circular opening

$\mathrm{N}_{\mathrm{u}}$ : the ultimate load of a R.C. wall without openings

$\mathrm{P}$ : the circular opening area percentage from the total wall area

Figure 26. Load-size Relationship Curve of R.C Wall with Circular Opening

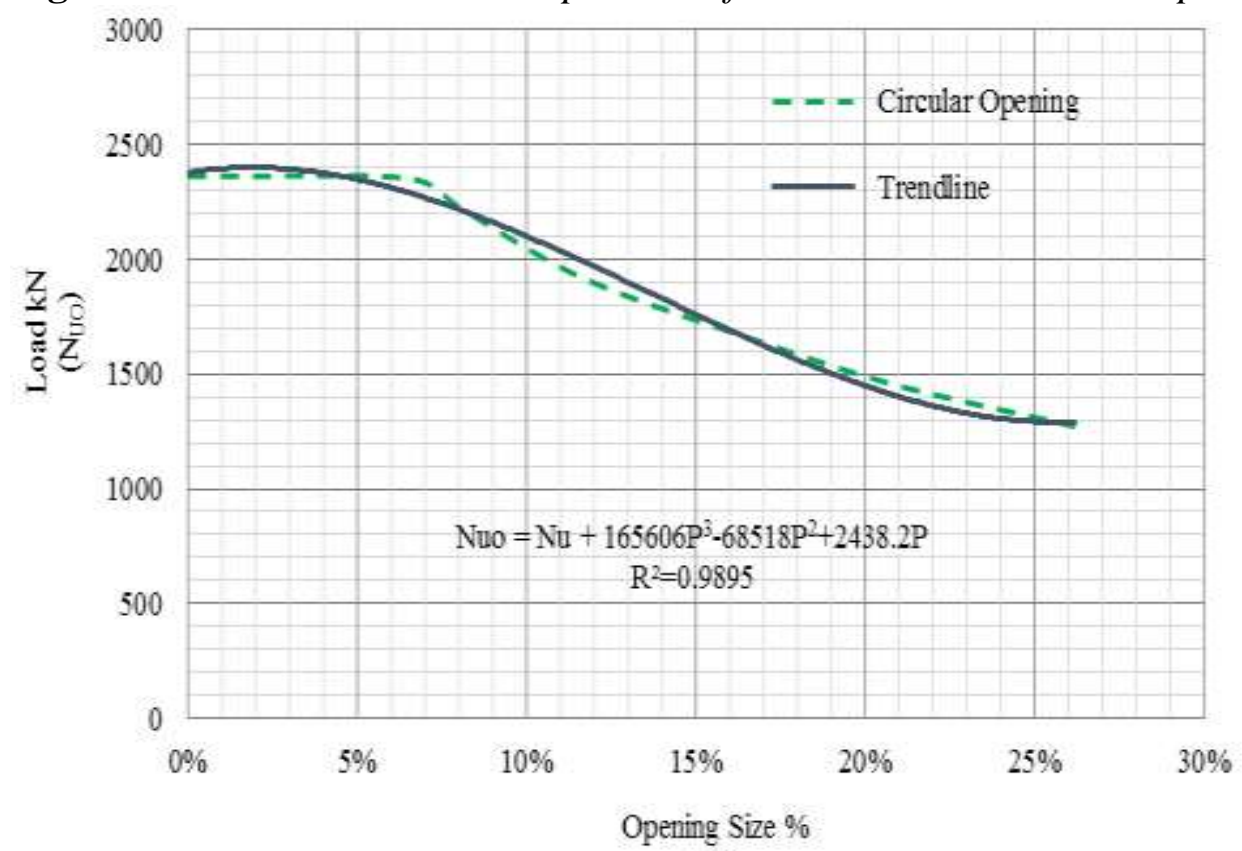

(P)

\section{Conclusions} drawn:

Based on the study presented herein, the following conclusions have been

- The R.C. wall with vertical rectangle direction opening has the highest axial load capacity compared with square and circular opening which have the same opening size. The main reason is that the loaded cross section area at the opening section in the R.C. wall with vertical 
rectangle opening is larger than those in the other shapes at the same opening section. Therefore, this large area can resist higher axial load values. So, the findings indicate that the effect of changing the opening shape should not be ignored.

- Changing the opening orientation has considerable impact on the wall ductility and the axial capacity values as R.C wall with vertical rectangle direction opening has better characteristics than horizontal rectangle direction opening because the loaded cross section area at the opening section in the R.C wall with vertical rectangle opening is larger than the loaded cross section area in the R.C. wall with horizontal rectangle opening at the same opening section.

- Increasing the aspect ratio of horizontal rectangle direction openings in R.C. walls with constant opening size leads to axial capacity reduction because of the reduction in the resisting cross section area in the R.C. wall.

- The optimum opening position in the shear wall regarding axial load capacity is at the lower middle because this position is away from the loaded edge and the axial load path. On the other hand, regarding ductility is at the exact middle of the shear wall.

- R.C. wall with small opening with an area less than $7 \%$ of the total have negligible effect on shear wall capacity. In contrast, if the size of the opening is large enough (size $>7 \%$ ), the amount of shear walls capacity and ductility decreases.

- Increasing the wall thickness has considerable effect on the axial capacity but leads to the wall ductility reduction.

- This research studies the gaps of the previous mathematical design models and takes into considerations some important parameters, which affect the accuracy of these models such as changing the thicknesses of R.C. wall with opening, walls with eccentricities above $t / 6$ and the effect of circular openings on R.C. Walls.

- Based on the F.E. parametric study, a new mathematical formula has been conducted using curve-fitting technique to predict the ultimate axial strength of R.C. wall with circular opening.

\section{References}

ANSYS - Release Version 11. A Finite Element Computer Software and User Manual for Nonlinear Structural Analysis. Canonsburg, PA: ANSYS 2007 Inc.

AS3600 (2009) Concrete Structures. Sydney, Australia: Standards Australia.

Chowdhury SR, Rahman MA, Islam MJ, Das AK (2012) Effects of Openings in Shear Wall on Seismic Response of Structures. International Journal of Computer Applications (0975 - 8887) 59(1).

Doh JH, Fragomeni S (2006) Ultimate Load Formula for Reinforced Concrete Wall Panels with Openings. Advances in Structural Engineering 9(1): 103-15. 
EN1992-1-1 (2004) Eurocode 2: Design of Concrete Structures - Part 1-1: General Rules and Rules for Buildings. Brussels: COMITE EUROPEEN DE NORMALISATION.

Fragomeni S, Doh JH, Lee DJ (2012) Behavior of Axially Loaded Concrete Wall Panels with Openings: An Experimental Study. Advances in Structural Engineering 15(8): 1345-58.

Guan H, Cooper C, Lee D-J (2010) Ultimate Strength Analysis of Normal and High Strength Concrete Wall Panels with Varying Opening Configurations. Engineering Structures 32(5):1341-55.

Kankuntla A, Sangave P, Chavan R (2016) Effects of Openings in Shear Wall. IOSR Journal of Mechanical and Civil Engineering (IOSR-JMCE) 13(1): 1-6.

Kwan AKH, Dai H, Cheung YK (1999) Non-Linear Sesimic Responce of Reinforced Concrete Slit Shear Walls. Journal of Sound and Vibration 226(4): 701-718.

Lee D-J (2008) Experimental and Theoretical Study of Normal and High Strength Concrete Wall Panels with Openings. PhD Thesis. Australia: Griffith University.

Lin CY, Kuo CL (1988) Behaviour of Shear Wall with Opening. Ninth World Conference on Earthquake Engineering in Tokyo.

Mohammed BS, Ean LW, Anwar Hossain KM (2010) CFRP Composites for Strengthening of Reinforced Concrete Walls with Openings. International Journal of Engineering Research and Applications 1(4): 1841-1852.

Morsy AM, Helmi KM, El-Ashkar NH, Nada M (2015) Flexural Strengthening for R.C. Beams using CFRP Sheets with Different Bonding. International Conference on Advances in Structural and Geotechnical Engineering in Hurghada.

Mosoarca M. (2014) Failure Analysis of RC Shear Walls with Staggered Openings under Seismic Loads. Engineering Failure Analysis 41(0): 48-64.

Musmar MA (2013) Analysis of Shear Wall with Openings Using Solid65 Element. Jordan Journal of Civil Engineering 7(2).

Popescu C, Sas G, Sabău C, Blanksvärd T (2016) Effect of Cut-Out Openings on the Axial Strength of Concrete Walls. Journal of Structural Engineering 142(11).

Rusch H, Hilsdorf HK (1963) Deformation Characteristics of Concrete under Axial Tension. Munich: Voruntersuchungen, Bericht 44.

Saheb SM, Desayi P (1990) Ultimate Strength of RC Wall Panels with Openings. Journal of Structural Engineering 116(6): 1565-78.

Terec L, Bugnariu T, Păstrav M (2010) Analiza Neliniară a Cadrelor din Beton Armat cu Pereţi Turnaţi în Situ. [Non-Linear Analysis of In-Concrete Wall Armed Buildings.] Romanian Journal of Materials 40(3): 214-221.

William K.J, Warnke EP (1975) Constitutive Model for the Triaxial Behavior of Concrete. Proceedings of the Int. Assoc. Bridge Struct. Eng. Sem. Concr. Struct. 19, 1-31. Bergamo, Italy. 